\title{
APROXIMACIÓN A LA TIPOLOGÍA DE LA CERÁMICA COMÚN PÚNICO-GADIRITA DE LOS SS. III-II
}

\author{
APPROACH TO A TYPOLOGY OF THE PUNIC COARSE \\ POTTERY OF GADIR OF $3^{\text {RD }} 2^{\text {ND }}$ CENTURIES B.C.
}

\author{
por \\ ANTONIO M. SÁEZ ROMERO
}

RESUMEN

En líneas generales el s. -III en la metrópolis de Gadir y sus zonas de influencia ha sido abundantemente estudiado, tanto desde una perspectiva histórica documental como a través de la arqueología. Sin embargo, en cuanto al estudio de la cultura material cerámica recuperada de esta centuria sólo se han realizado seriaciones de ciertos tipos, no siempre producciones locales, centrándose en periodos temporales más amplios y en las ánforas. En este artículo se pretende mostrar algunas de las formas más características producidas en los talleres gadiritas y que constituyen el grueso de los hallazgos cerámicos tanto en contextos funerarios, industriales o de habitación. Se analizarán, ordenadas por familias tipológicas, las cerámicas comunes fabricadas en Gadir especialmente en la segunda mitad del s. -III y los inicios del s. -II.

\begin{abstract}
The $3^{\text {rd }}$ century BC in the phoenician colony of Gadir has been well studied from historical views as well as from archaelogical works. But the study of the ceramic remains of this century is not developed because researchers have only studied some pottery types and the amphoras have taken the main atention. In this paper we'll show some of the more characteritic non-amphoric pottery types produced in Gadir during this century and the beginnings of the $2^{\text {nd }}$ century $\mathrm{BC}$.
\end{abstract}

Palabras claves Siglos -III/-II. Tipología cerámica. Producción local. Gadir.

Key words $\quad 3^{\text {rd }}-2^{\text {nd }}$ centuries BC. Ceramic typology. Local production. Gadir.

\section{INTRODUCCIÓN.}

La seriación tipológica y la definición cronológica de cada forma cerámica es aún hoy por hoy una tarea pendiente en buena medida en la arqueología de Gadir. Esta cuestión, sin duda de base para poder 
fijar la evolución histórica de una zona de la que apenas se nos han conservado documentos escritos o para poder medir procesos como la romanización de una importante ciudad de tradición semita en muchos niveles, está lejos de estar zanjada y presenta numerosas lagunas de investigación y publicación. A pesar de algunos avances de los últimos años resulta realmente sorprendente el que las continuadas actividades arqueológicas en el asentamiento portuense del Castillo de Doña Blanca-CDB- (Ruiz y Pérez 1995; Ruiz Mata 1999) y el control arqueológico de cualquier actividad constructora en Cádiz desde finales de los años 70 (Muñoz 1997) no han servido aún para que se haya realizado un corpus tipológico de la cerámica gadirita, ni siquiera de un periodo aislado. Salvo algunos estudios generales en Cádiz (Muñoz 1987a) y el ensayo de sistematización de las ánforas gadiritas realizado por J. Ramón (1995) dentro de otra obra de síntesis de contexto mediterráneo, los restantes esfuerzos se han centrado en el estudio de un periodo de un yacimiento concreto (Ruiz Mata 1986) o de tipos cerámicos (Muñoz 1982; 1985, 1987b, 1993a, 1993b, en prensa; Fierro 1990; Pérez 1990 y 1993; Lagóstena 1996; García Vargas 1998; Niveau 1999, 2000a, 2000b, 2004a-b; Sáez et alii, en prensa). Son sin duda éstas aportaciones muy apreciables pero fragmentarias y aisladas, algo que parece convertirse en la principal falta hasta el momento.

Nuestra aportación en estas páginas que siguen es también deudora en parte de esta tendencia historiográfica anterior, ya que nos centraremos en el estudio de las cerámicas comunes del periodo comprendido esencialmente por la segunda mitad del s. -III y los primeros pasos del -II producidas en los hornos gadiritas, si bien insertándolas dentro de la tradición alfarera local anterior. Esta atención monográfica está por otro lado justificada ya que tanto las ánforas como la vajilla barnizada del periodo en cuestión están actualmente bien estudiadas y seriadas gracias a recientes estudios de diversos investigadores: para los envases de transporte, además de los trabajos de J. Ramón (1995 y 2004) y de A. Muñoz (1985), las recientes investigaciones desarrolladas en el ámbito de los talleres alfareros gadiritas (Sáez et alii e.p.; Sáez, Díaz y Montero 2005; Sáez 2004 y 2005) parecen haber clarificado la cuestión de la tipología de las ánforas locales del periodo de una forma contundente. Por otro lado, la producción de un amplio repertorio de formas de vajilla de barniz rojo protocampaniense ha sido monográficamente estudiado por A. M. Niveau como parte de su Tesis de Licenciatura (Niveau 2002) por lo que creemos que es una categoría vascular suficientemente conocida y autónoma tipológicamente para excluirla de nuestro estudio. Dados estos condicionantes, hemos clasificado dentro de nuestro repertorio sólo las formas de cerámica común o «de cocina» (ollas y cazuelas) fabricadas por los alfareros gadiritas en estas décadas y halladas en gran número en los yacimientos de la bahía. Para la confección de la tabla propuesta, susceptible de ser ampliada y matizada en un futuro por nuevos descubrimientos o publicaciones de contextos inéditos, hemos seleccionado piezas en su mayor parte completas procedentes casi en exclusiva del alfar de Torre Alta, en la isla de San Fernando, junto a algunos perfiles extraídos de los hallazgos de los niveles finales tanto del CDB como del poblado industrial de Las Cumbres (Ruiz y Pérez 1995). Nuestro propósito es el de armonizar la información crono-tipológica aportada por el CDB, Las Cumbres, los saladeros gadiritas, la necrópolis gaditana y los alfares insulares, intentando crear una herramienta de trabajo útil para otros investigadores del entorno o foráneos que se acerquen al análisis arqueológico de la época estudiada en relación con Gadir.

\section{UNA ÉPOCA DE TRANSICIÓN. INFLUENCIAS Y PERVIVENCIAS}

La etapa en que centramos nuestro estudio es sin duda uno de los puntos de inflexión más importantes en la historia de la bahía gaditana al producirse en pocas décadas la sucesión de dominios imperia- 
listas sobre el territorio, a lo que Gadir hubo de hacer frente y adaptarse. Pero alejándonos de la historia política y de los grandes hechos ya bien conocidos, esta etapa transicional se tradujo también en un intenso trasiego de gentes, ideas y productos comerciados, lo que nos resulta de vital importancia para el análisis de estas categorías cerámicas. El que esta sea una etapa de intensas influencias centromediterráneas primero y latinas después ha dejado su huella hasta en las muestras arqueológicas más pobres o comunes, caso de nuestras cerámicas, en las que podremos apreciar según el caso el predominio de una u otra.

\subsection{La industria alfarería gadirita: precedentes, la ocupación bárcida y la continuidad productiva en el s. -II}

En lo que nos atañe en estas páginas y dejando al margen otros análisis de corte histórico-arqueológico más generalistas sobre la bahía (Sáez, Montero y Díaz 2005), debemos plantearnos el estado de la industria que manufacturó las cerámicas que ahora estudiamos, su evolución bajo las diversas situaciones políticas y sus características generales, lo cual nos permitirá acercarnos a otros condicionantes que sin duda influyeron en la tipología de las piezas. No siendo desde luego el objeto central de este trabajo, por lo que no ahondaremos en la cuestión, debemos comenzar señalando el que la producción cerámica de los ss. -III/-II se vio beneficiada tanto a nivel cualitativo como cuantitativo por la regeneración del comercio internacional gadirita en esos momentos. Si el s. -V representó una época de clara expansión económica de la ciudad, el s. -IV (especialmente desde el tercer cuarto) significó un lento declive de las cimas alcanzadas en la centuria anterior, con una notable pérdida de protagonismo internacional, una crisis económica-industrial en alza y una cada vez mayor dependencia del ámbito centromediterráneo. En efecto, los saladeros y alfares gadiritas denotan para estos momentos una espectacular caída del volumen de manufacturas hasta llevar a algunos de estos asentamientos a la extinción, volviéndose crítica la situación en la transición al s. -III y los primeros años de éste. Las causas de este proceso, demasiado complejas para ser tratadas de forma correcta en esta síntesis, hay que buscarlas desde luego en elementos externos diversos y sincrónicos: creciente presión internacional cartaginesa, agotamiento de las importaciones de vajilla ática que redistribuir en el mundo indígena, aumento de la competencia comercial ebusitana y de otras áreas del Estrecho, etc... Sin embargo, los lazos internacionales no se diluyeron totalmente y la crisis fue acusada pero no consiguió acabar con la industria salazonera gadirita, probablemente gracias a la notable habilidad de la ciudad y sus gobernantes para esperar su oportunidad. Esta no se hizo esperar, detectándose en relación con las dificultades cartaginesas (del mundo púnico centromediterráneo en sentido amplio) debidas a la I Guerra Púnica un resurgir comercial y el retomar de las antiguas redes comerciales, en especial el eje Ibiza-Ampurias. El conflicto y los años de entreguerras posteriores marcaron un nuevo rumbo en la economía de Gadir, que de nuevo se volcaría a la comercialización a gran escala de productos piscícolas, adquiriendo de nuevo la industria alfarera entorno a mediados del s. -III un nivel de producción casi comparable con el documentado para el s. -V. La II Guerra Púnica y la conquista romana, hábilmente manejadas por los dirigentes gadiritas y sus agentes comerciales, no supusieron un paso atrás sino que confirmaron la evolución favorable de este proceso, dando continuidad cultural y económica a lo ya enunciado durante la primera mitad del s. -II (Montero et alii 2004). Sólo a partir de entonces los efectos romanizadores son perceptibles a nivel general en cuanto a la producción cerámica y salazonera, con la introducción de modificaciones que alterarán de forma definitiva los esquemas productivos púnicos desarrollados desde la etapa arcaica.

ISSN: 1133-4525 ISSN-e: 2255-3924

SPAL 14 (2005)

http://dx.doi.org/10.12795/spal.2005.i14.06 


\section{DESCRIPCIÓN TIPOLÓGICA DE LAS CERÁMICAS COMUNES GADIRITAS DE LOS SS. -III/-II}

Cabe realizar en este apartado, antes de comenzar el análisis detallado de cada tipo o variante de estas cerámicas, expresar de nuevo la mentalidad abierta con que ha sido concebida esta clasificación ${ }^{1}$. Ejemplo de ello es la deliberada no inclusión de dos categorías vasculares en ella que, aunque conocidas, no cuentan con ejemplares publicados suficientemente completos formalmente para servir de modelo dentro de esta tipología o ya han sido ampliamente estudiados con anterioridad. Nos referimos a las lucernas de dos picos y a los ungüentarios: la primera de estas categorías enunciadas prolonga su existencia hasta estos momentos procedente de una larga tradición alfarera dentro del mundo fenicio-púnico; la segunda, introducida en esta centuria bajo los parámetros helenísticos de cuerpos de tendencia globular y extremos cortos con frecuente decoración pictórica a bandas rojas, se corresponde con una novedad en el repertorio gadirita.

Las lucernas de dos picos de la época tratada en este artículo son ya el vago recuerdo de las piezas de época arcaica finamente moldeadas cuidadosamente y con un notable recubrimiento de engobe rojo. Los ejemplares conocidos de estos momentos, localizados en un número sensible entre las producciones locales del alfar de Torre Alta (Sáez 2004) son pequeños platillos a los que se han doblado algunas zonas hasta conseguir los característicos picos, siendo normalmente de paredes gruesas y careciendo en todos los casos de engobe u otro tipo de cubierta. Los datos disponibles permiten suponer un uso y comercialización de estas lucernas hasta mediados del s. -II, momento en que la influencia itálica debió hacerse tan palpable que se sustituyeron de forma definitiva por ejemplares de tipo helenístico de barniz negro importado o de barniz rojo local.

Respecto a los ungüentarios, hemos preferido respetar la clasificación ya realizada por A. Muñoz Vicente (1987b: 520-525) en la cual pocas novedades podemos introducir. Quizá simplemente matizar la cuestión cronológica entorno a las clases correspondientes a la segunda mitad del s. - III y los inicios del s. -II: a la etapa más antigua del periodo estudiado parecen responder las formas encuadradas en el grupo $\mathrm{A}^{2}$, especialmente la A2 (Muñoz 1987b: 521, fig. 1), mientras que ya a partir de los inicios del s. -II comenzarían a proliferar entre las producciones locales gadiritas los del tipo B1 (Muñoz 1987b: 522, fig. 3). Lo dicho no es óbice para poder ampliar el arco cronológico de la producción de ungüentarios a una etapa más antigua dentro del s. -IV avanzado o los inicios del -III, algo que podrá ser clarificado con el estudio en curso del alfar isleño de Villa Maruja (un avance en Bernal et alii 2003: 49-101).

Al margen de estas dos formas no incluidas en la propuesta tipológica, debemos señalar también la no inclusión de algunas otras debido a la extrema fragmentación de los ejemplares conocidos. Es este el caso de las ollas con solero desarrollado, cuerpo de tendencia globular y asas horizontales, al estilo de las documentadas coetáneamente en Ibiza (Gómez y Gurrea 1985: 154, figs. 5 y 6, 16-17) y en Cartago (Guerrero 1999: 222-224, figs. 104-106). Su manufactura es frecuente en los alfares gadiritas, estando presente en número sensible en algunos como Campo del Gayro o Huerta del Contrabandista, si bien su morfología concreta no ha podido ser documentada satisfactoriamente. Por ello, hemos preferido dejar en suspenso la inclusión de estas ollas en la tipología, a expensas de nuevos hallazgos dados a conocer.

1. Nos gustaría agradecer desde estas líneas las sugerencias e interés en la revisión y corrección del texto y la propuesta tipológica de los profs. Drs. D. Bernal Casasola (Univ. de Cádiz) y A. Adroher Auroux (Univ. de Granada). Sus comentarios y observaciones han sido de enorme utilidad para la redacción final y la orientación metodológica de este trabajo.

2. Un paralelo casi exacto de las producciones del alfar de Torre Alta en su fase de la segunda mitad del s. -III lo encontramos en las tumbas de inhumación con cubierta pétrea o anfórica documentadas en las excavaciones de 1986 en la Plz. de Asdrúbal (Perdigones, Muñoz y Marcos 1987: fig. 1, 1). 
Una vez analizadas estas categorías no incluidas, resta señalar que nuestra tabla se ha nutrido de formas comunes destinadas tanto al almacenaje de productos como al menaje cotidiano y al servicio de mesa, así como algunas actividades industriales-artesanales. Asimismo, se han incluido formas manufacturadas con pastas especiales refractarias destinadas al cocinado o cocción de alimentos, para lo cual debieron soportar altas temperaturas. En definitiva, se han podido distinguir -al margen de los ungüentarios y lucernas ya comentados- 25 formas principales con usos y finalidades muy diversas:

\section{TIPO 1: CUENCOS}

\section{FORMAS GDR 1.1.1 y 1.1.2}

Denominación genérica: pequeño cuenco de borde entrante.

Comentario formal: Se trata de cuencos de reducido tamaño y una marcada tendencia de sus bordes apuntados al invasamiento, con pies indicados y ocasionalmente de galleta. Esta forma, heredera de los saleritos áticos de barniz negro, tiene sus primeros prototipos en piezas manufacturadas en el s. -IV en el alfar de Villa Maruja (Bernal et alii 2003: 74, fig. 26) y otros centros menos conocidos. Por tanto, se presenta como un tipo ya en época tardopúnica de tradición arraigado en los gustos locales, presentando múltiples variantes más o menos afines a los prototipos del s. -IV y con diámetros variables (un ejemplo de ello en el CDB, Ruiz y Pérez 1995: 90, fig. 26, 13-16). Asimismo, hay que señalar la convivencia de estos pequeños cuencos comunes con otros similares de la forma Niveau IX (2003: 71-78) completamente barnizados de rojo y estampillados, siendo el principal elemento de distinción la falta de pie anular en la totalidad de ejemplares comunes. Su uso, muy restringido como elemento de iluminación, estaría principalmente destinado a cuestiones de menaje cotidiano.

Medidas: Variante 1.1.1: Diám. Máx.: 8,5-10 cms. Diám. Base: 5,5-6 cms. Alt. Total: 2-2,5 cms.

Variante 1.1.2: Diám. Máx.: 7-7,5 cms. Diám. Base: $4 \mathrm{cms}$. Alt. Total: 2,5-3 cms.

Acabado externo: Generalmente presentan bordes notablemente apuntados, con un cuidado alisado de las superficies y un acabado final con engobado superficial de destacable espesor del color de la pasta. Cabe por otro lado indicar que algunos ejemplares se barnizaron al interior e incluso de forma completa (caso de uno perteneciente a la variante 1.1.2 localizado en la escombrera MC-II de Torre Alta), si bien esto probablemente no fuese más que una práctica esporádica.

Características de pasta: Pastas anaranjadas-rojizas o rosadas muy depuradas con adición de escasos desgrasantes finos.

Cronología: Los hallazgos dados a conocer hasta el momento, teniendo en cuenta su origen local ya en el s. -IV, parecen apuntar a una etapa de manufactura centrada en el siglo -III con una considerable perduración en la centuria siguiente (un ejemplar completo se recuperó en un alfar de fines del-II localizado en la C/ Asteroides isleña).

Centros de producción: Torre Alta (escombrera MC-II), El Canal.

Bibliografía: inédita.

\section{FORMAS GDR 1.2.1, 1.2.2 y 1.2.3}

Denominación genérica: cuencos de cuarto de esfera

Comentario formal: Cuencos simples, producidos de forma masiva en la práctica generalidad de los centros alfareros conocidos, cuyo estatus de categoría vascular multiuso y menor dio pie al torneado de numerosas variantes según la propia pericia y gustos del alfarero: respetando el esquema general de una tendencia marcadamente abierta con un diámetro máximo muy amplio, encontramos ejemplares con cierta curvatura de la pared (var. 1.2.1), con una pared recta acabada en un borde engrosado redondeado (var. 1.2.3) o modelos intermedios en ocasiones presentando bordes finos y ligeramente apuntados (var. 1.2.2).

ISSN: 1133-4525 ISSN-e: 2255-3924 
Los pies son siempre indicados, con una ligera diferenciación de la pared, y usualmente no muy anchos. Su tipología, demasiado común para poder elucubrar sobre influencias externas, parece provenir de los cuencos de pasta gris o engobe rojo al interior del s. $-\mathrm{V}$, y más directamente de los decorados a bandas o sin decoración documentados en el s. - IV. Su funcionalidad debió ser múltiple a tenor de los numerosos hallazgos en contextos de habitación del CDB (Ruiz y Pérez 1995: 90, fig. 26, 11-12), industriales del poblado de Las Cumbres (Ruiz y Pérez 1995: 92, fig. 28, 2-3), quizá sacros de la necrópolis gaditana (Niveau 2004a: 17, fig. 14, 2) y alfareros (Sáez 2004). Respecto a este punto, cabe señalar que ante la falta de una manufactura en serie de tapaderas, algunos de estos cuencos debieron ser utilizados como cubrición de otras categorías vasculares de esta tipología (quizá de variantes de las formas 7, 8, 9 y del grupo 12). La documentación de orificios realizados tras la cocción en la base de algunas piezas parece evidenciar su posterior empleo como tapaderas para la cocción de alimentos.

Medidas: Diám. Máx.: 16-18 cms. Diám. Base: 5-6,5 cms. Alt. Total: 4,5-6,5 cms.

Acabado externo: Esta forma suele presentar buenos acabados con una cuidado alisado de las superficies y un fino engobado del color de la pasta.

Características de pasta: Normalmente presentan pastas duras de fractura regular, muy depuradas (con desgrasante fino poco frecuente), con coloraciones rosadas a amarillentas.

Cronología: Los hallazgos enunciados anteriormente y los contextos alfareros isleños indican una larga perduración de esta forma, con innumerables peculiaridades individuales debido a la estandarización de su manufactura. Puede proponerse, atendiendo a las tres variantes ahora estudiadas, un periodo de manufactura centrado en el s. - III y la primera mitad del s. -II, si bien conocemos cuencos simples similares de época republicana avanzada, fruto sin duda de la sencillez formal de este tipo y su carácter «universal».

Centros de producción: Torre Alta, Campo del Gayro, Huerta del Contrabandista, El Canal, Eucaliptos. Bibliografía: Sáez 2004.

\section{FORMA GDR 1.3.1}

Denominación genérica: cuenco hemisférico

Comentario formal: Diferenciado de los anteriores en una mayor capacidad fruto de un mayor desarrollo de las paredes y un tamaño ligeramente mayor. El grosor de las paredes no es siempre tan notable como en el ejemplar propuesto ahora, documentándose otros con galbos y bordes finos aná$\operatorname{logos}$ a lo visto en el grupo formal 1.2.0. Este tipo de cuenco se presenta como una variante de dicha forma, conviviendo ambas en los mismos estratos, si bien con una mucha menor presencia de los hemisféricos. Quizá podamos encontrar una justificación a su aparición en la influencia motivada por la manufactura coetánea de cuencos de inspiración itálica L-27 barnizados de rojo (forma Niveau, X. Cf. Niveau 2003: 78-80).

Medidas: Diám. Boca: 18,5 cms. Diám. Base: $7 \mathrm{cms}$. Alt. Total: $8 \mathrm{cms}$.

Acabado externo: Alisado de las superficies muy cuidado, con cubierta de notable espesor de un engobe del color de la pasta. Los pies, notablemente aristados en la zona de apoyo, y los bordes redondeados presentan una gran regularidad.

Características de pasta: Arcillas rojizas-anaranjadas, depuradas con adición de desgrasante fino-medio a baja frecuencia.

Cronología: Similar a la de las formas del grupo 1.2.0, muy emparentada no sólo formalmente, si bien hay que tener aún algunas reticencias a la manufactura de estos cuencos antes de mediados del s. -III. Seguramente su apogeo se sitúa a partir del último tercio de dicha centuria continuando al menos hasta mediados del s. -II (Arteaga et alii 2001: fig. 8, 5).

Centros de producción: Torre Alta (escombrera MC-II).

Bibliografía: Sáez 2004. 


\section{TIPO 2: PÁTERAS}

\section{FORMAS GDR 2.1.1 y 2.1.2}

Denominación genérica: gran cuenco carenado

Comentario formal: Se trata de páteras o cuencos de grandes dimensiones con bordes generalmente redondeados y con tendencia al invasamiento por encima de la carenación de la pared. Las bases corresponden a pies de tipo indicado, usualmente con un pequeño reborde no muy saliente ni diferenciado de la pared. Las carenaciones, situadas en el punto máximo del diámetro, pueden oscilar de forma notable en su aristamiento existiendo ejemplares casi indiferenciados (var. 2.1.2). En cuanto al origen de esta forma, si bien encontramos en Oriente cuencos carenados similares (Tiro, estrato XIII-1: Bikai 1978: pl. XXXIII; y Sarepta, estrato C: Pritchard 1978: 84), la realidad arqueológica disponible actualmente no permite conectar ambas producciones. A nivel formal también encontramos enormes similitudes con producciones del s. -VII/-VI del Cerro del Villar, englobadas como tipo C dentro de la categoría de los cuencos (Curiá et alii 1999: 167, fig. 105c y fig. 182d), si bien de nuevo topamos con el considerable salto cronocultural existente entre ambos tipos que nos plantea dudas sobre su conexión. Esto se debe a la falta de estos cuencos carenados entre las producciones gadiritas de los ss. -VI/-V (Ramón et alii 2004), al menos por lo conocido hasta el presente ${ }^{3}$, surgiendo los primeros ejemplares en el s. -IV según muestra el alfar de Villa Maruja (Bernal et alii 2003). Los primeros prototipos muestran un esquema formal y dimensiones similares a los ejemplares incluidos en nuestra tipología, si bien es común que se decoren con varias acanaladuras paralelas bajo el labio paralelas a la línea de carenación. Este rasgo parece configurarse con relativa seguridad como un distintivo cronológico, careciendo los ejemplares del s. - III de dichas acanaladuras. Respecto a su origen formal, debemos destacar también el carácter multifuncional de esta forma: al igual que anunciábamos para la forma 1.2.0, los fondos perforados pos-cocción documentados sobre algunos ejemplares y la morfología de sus labios abogan por incluir estos cuencos dentro del grupo de formas utilizadas para cubrir otras destinadas al fuego, en especial a las cazuelas de la forma 11.1.1.

Medidas: Diám. Máx.: 24-28 cms. Diám. Boca: 23,5-25 cms. Diám . base: 8-9 cms. Alt. Total: 8-10 cms.

Acabado externo: Superficies alisadas y cubiertas de un engobado del color de la pasta, con tendencia a adquirir tonos blancuzcos o amarillentos.

Características de pasta: Pastas depuradas de coloración anaranjado-rojiza a amarillenta, con adición frecuente de desgrasante fino-medio (sobre todo arena, conchas machacadas...).

Cronología: Forma producida abundantemente en los alfares gadiritas, presente en algunos pozos del s. - III de la necrópolis gaditana (Niveau 2004: 17, fig. 14, 1), en niveles sincrónicos del CDB (Ruiz y Pérez 1995: 90, fig. 26, 9-10) y del poblado de Las Cumbres (Ruiz y Pérez 1995: 92, fig. 28, 1). Situando su origen en el s. - IV, su periodo de mayor éxito se desarrolló a lo largo del s. -III (especialmente en la segunda mitad) y en la primera mitad del -II (Arteaga et alii 2001: fig. 8,1 y fig. 10, 5), no pudiendo precisarse el final de la producción ${ }^{4}$.

3. No es en absoluto descartable el que se trate de formas desarrolladas a partir de otras páteras o cuencos carenados que sí encontramos en buen número en el s. -V. De cualquier forma, tanto este origen paulatino a partir de tipos locales como su posible origen o influencia foránea no están clarificados. Hay que destacar a este respecto sus similitudes formales y cronológicas con un grupo de "cuencos de labio vertical" de fabricación ebusitana (Guerrero 1999b: 14-15, figs. 8-8a), que si bien presentan un diámetro algo menor y ocasionales cubiertas barnizadas, tienen más afinidad con nuestros ejemplares que con categorías propias de la vajilla fina de mesa barnizada (Guerrero 1999b: 15).

4. Una muestra de su perduración hasta al menos los comienzos del tercer cuarto del s. -II podemos encontrarla en un ejemplar documentado en la fase púnico-mauritana I del yacimiento de Lixus (Bonet et alii 2000: 59-60, fig. 5, 6), datada por sus excavadores entre $-175 /-150$ y $-80 /-50$. 
Centros de producción: Torre Alta, Campo del Gayro, Huerta del Contrabandista, C/ Luis Milena, ¿Eucaliptos?, ¿La Milagrosa?.

Bibliografía: Sáez 2004.

\section{TIPO 3: MORTEROS}

\section{FORMA GDR 3.1.1}

Denominación genérica: mortero

Comentario formal: Recipientes de paredes anchas, labio con solero y leve exvasamiento al interior y base amplia de tipo pseudoanular o anular. El origen de estos morteros, los de mayores dimensiones dentro de esta categoría vascular, parece que podemos encontrarlo en los manufacturados en Gadir en los ss. $-\mathrm{VI} /-\mathrm{V}$, en líneas generales bastante similares a los del - III (presentan diferencias tales como la aparición ocasional de borde simples, paredes más altas, la adición de pies adicionales en la base para dar mayor estabilidad, el estriado a bases de tríos de círculos incisos concéntricos de la base, etc...). Al parecer, algunas variantes poco definidas debido a su estado fragmentario de esta forma presentan en ocasiones un pico vertedor (Niveau 2004: 14-15, fig. 11, 2), algo que sin embargo no ha podido ser corroborado en los talleres alfareros gadiritas.

Medidas: Diám. Máx.: 35-40 cms. Diám. Base: 20-22 cms. Alt. Total: $10 \mathrm{cms}$.

Acabado externo: En raras ocasiones presentan un engobado superficial, siendo el proceso de alisado irregular o poco cuidado.

Características de pasta: Manufactura más grosera que el resto de categorías, con pastas poco depuradas y frecuente adición de desgrasantes de medio-gran tamaño (mica, elementos rojizos y grisáceos cuarcíticos, conchas machacadas, algunas vacuolas de calcita y excepcionalmente algún elemento férrico).

Cronología: Si bien su esquema formal general no varió en demasía durante los ss. -IV/-III, la forma recogida en nuestra tipología responde a perfiles propios de mediados y segunda mitad del -III y quizá los primeros compases del s. - II.

Centros de producción: Torre Alta, Campo del Gayro.

Bibliografía: Ruiz y Pérez 1995: 93, fig. 29, 3.

\section{FORMA GDR 3.2.1}

Denominación genérica: mortero de base estriada al exterior.

Comentario formal: Se trata sin duda de una de las formas incluidas en nuestra tipología que mejor evidencia la influencia cartaginesa-ebusitana en la producción cerámica gadirita de los ss. -IV/-III. Sin precedentes formales entre las manufacturas locales del $-\mathrm{V}$, parece que en un momento no muy avanzado del s. - IV estos prototipos cartagineses alcanzaron gran éxito comercial y fueron imitados en número importante en los alfares gadiritas. El registro del alfar de Villa Maruja (Bernal et alii 2003) es elocuente a este respecto, correspondiendo los primeros perfiles locales al modelo ebusitano AE-20/I-167 (Ramón 1998a: 175-176, fig. 14), evolucionados en la isla pitiusa a partir de perfiles locales aún más antiguos $^{5}$. Estos morteros parecen tener un origen cartaginés (Lancel 1987, tipo 131; Martín y Roldán 2000), teniendo una gran y rápida aceptación en el mundo púnico occidental (presentes por ejemplo en contextos foráneos como Lattes, vid. Adroher 1993: 375). Los ejemplares gadiritas de la segunda mitad del s. -III y los inicios del s. -II que aquí presentamos serían la evolución de los de fábrica local propios de la centuria anterior junto a las nuevas tendencias estilísticas observadas en los ejemplares cartagineses e ibicencos, con bordes cada vez más colgantes y ausencia de carenaciones en la pared bajo el labio

5. Datados hacia fines del s. $-\mathrm{V}$, localizados en Es Palmer y los niveles inferiores de la alfarería ibicenca AE-7 (Ramón 1998b: 133, nota 4, fig. 2, 10). 
(tipo ibicenco FE-13/III-257 definido en Ramón 1997: 53-54, fig. 44; y morteros cartagineses como el recuperado en la colina de Byrsa -Lancel y Thuillier 1979: 218, fig. 63, 16-). Mientras los cartagineses y ebusitanos se diferencian entre sí por la falta en los primeros de estrías en la base y de escorias férricas en el fondo interno (Ramón 1997: 54), los gadiritas sí presentan el fondo estriado, lo que parece indicar que las influencias estilíticas cartaginesas fueron filtradas hacia el extremo occidente a través de Ibiza. Otra cuestión importante, aclarado ya el origen formal, es señalar la existencia de una notable variedad formal especialmente en lo tocante a los labios: los ejemplares más antiguos respetan fielmente los bordes rectos y ligeramente sobreelevados de los ibicencos AE-20/I-167, mientras que a partir de mediados del-III muchos se adecuan a los bordes redondeados y más colgantes de los FE-13/III-257, no documentándose en ningún caso la existencia de vertedores al modo de los FE-13/III-255 (Ramón 1997: $52-53$, fig. 43). Otro aspecto a valorar, también probablemente relacionado con la influencia centromediterránea, es la existencia a partir de fines del s. -III de ejemplares evolucionados (uno de ellos el tipo GDR 06b) con diámetros algo menores y paredes y labios más finos. Una variante, no incluida en nuestra propuesta tipológica debido a lo fragmentario de los hallazgos, respeta de manera fiel el esquema general pero reduciendo de forma drástica la anchura y grosor de labios y paredes y adquiriendo una apariencia general más afín a un gran plato con poca profundidad interna. Debió ser, al menos en la fase de la segunda mitad del s. - III y los inicios del siguiente, una forma de gran aceptación local a tenor de su elevada presencia en alfares como Torre Alta.

Medidas: Diám. Máx.: 34-38 cms. Anch. Labio: 2,5-3,5 cms. Diám. Base: 11,5-13 cms. Alt. Total: 8-9 cms.

Acabado externo: Acabados por lo general consistentes en un cuidado alisado del interior y el labio, con recubrimiento de espesor variable de un engobe del color de la pasta. Las bases presentan un característico estriado para favorecer la adherencia de las mismas realizado con un elemento duro y de escaso grosor con diversos diseños (líneas formando círculos concéntricos en el taller de Torre Alta o una línea continua formando una espiral acabada en el centro caso del alfar de Campo del Gayro). Al contrario que los ejemplares ebusitanos (Ramón 1997: 53-54), no presenta ninguna cubierta de origen férrico en el fondo interno.

Características de pasta: Diversidad de pastas en función de su manufactura en otros tantos talleres, si bien generalmente responden a tonalidades rosado-rojizas de fractura irregular con adición de desgrasante de fino-medio tamaño a media frecuencia.

Cronología: Si bien la manufactura en Gadir de este tipo de cuenco puede retrotraerse con seguridad al s. - IV, los prototipos aquí analizados corresponden a formas propias de mediados y segunda mitad del s. -III e incluso los inicios del s. - II. Resulta difícil distinguir alguna característica evolutiva en este periodo que permita definir tipologías más o menos antiguas. Destaca a nivel funcional su presencia en algunos pozos del s. - III de la necrópolis gaditana (Niveau 2004: 14, fig. 11, 5).

Centros de producción: Torre Alta, Campo del Gayro, Centro Atlántida, Eucaliptos.

Bibliografía: inédita.

\section{FORMA GDR 3.2.2}

Denominación genérica: pequeño cuenco-mortero

Comentario formal: Forma derivada de los morteros locales GDR 3.2.1 surgida a fines del s. -III (presente en depósitos como el relleno del horno 5 de Torre Alta) como tipo minoritario frente a sus predecesores. Su producción, con medidas totales cada vez menores y labios más estrechos parece poder asegurarse que continuó al menos hasta mediados del s. -II (presencia en el estrato 2 del Horno I de Avda. Al-Andalus, según Arteaga et alii 2001: 134, fig. 7, 2), si bien debemos matizar que esta forma pudo evolucionar en este sentido durante la época republicana dando origen a la familia de cuencos- 
tapadera tan conocidos en la necrópolis gaditana dedicados a cubrir las urnas cinerarias derivadas de nuestra forma 8.1.1 (López 2003: 113, fig. 15; Gordillo 1987: 467, fig. 2; Gener 1994: 17, figs. 1 y 2a). Medidas: Diám. Máx.: 24-27 cms. Anch. Labio: 2-2,5 cms. Diám. Base: 7-8 cms. Alt. Total: $7 \mathrm{cms}$.

Acabado externo: Similar a sus predecesores. Algún ejemplar presenta un barnizado rojo interno de escasa calidad.

Características de pasta: Pastas típicas de la zona depuradas de tonos rosáceos a amarillentos con inclusión frecuente de desgrasantes finos (micas, cuarcitas y conchas machacadas, etc...).

Cronología: El inicio de la manufactura puede situarse con seguridad a fines del s. -III, si bien las evoluciones formales de estos cuencos durante los ss. - II/-I dificultan en exceso la identificación de un momento exacto de salto tipológico, dando la impresión de acercarse más a una lenta transformación que a una sustitución por otra variante. Los ejemplares más modernos tendrían diámetros menores y labios cada vez menos desarrollados.

Centros de producción: Torre Alta (Horno 5)-Avda. Al-Andalus.

Bibliografía: Sáez 2004.

\section{TIPO 4: LEBRILLOS}

\section{FORMA GDR 4.1.1}

Denominación genérica: lebrillo

Comentario formal: Forma de uso doméstico e industrial derivada de prototipos fenicio-occidentales propios de, al menos, los comienzos del s. -VI (Curiá et alii 1999: 170-171, fig. 106; Ruiz Mata 1997: fig. 8), los lebrillos del s. -III han perdido ya de forma definitiva la decoración policroma. Suelen caracterizarse por un borde engrosado más o menos saliente y desarrollado, carenaciones ocasionales bajo el labio (quizá para facilitar el asido del recipiente) y bases con pies ligeramente anulares o indicados no demasiado anchas. Su presencia es frecuente en el CDB (Ruiz y Pérez 1995: 91, fig. 27, 1-8), en el poblado de Las Cumbres (Ruiz y Pérez 1995: 93, fig. 29) y en la necrópolis gaditana (Niveau 2004: 14, fig. 11, 1), y su manufactura fue de un volumen destacable en los alfares gadiritas (Sáez 2004).

Medidas: Diám. 32-36 cms. Diám. Base: 8-10 cms. Alt. Total: 16-18 cms.

Acabado externo: Bastante similar al documentado en los morteros de la forma 5, con un alisado regular, bases poco cuidadas y frecuente aparición de desgrasantes de ciertas dimensiones tanto en la superficie interna como externa.

Características de pasta: Pastas menos cuidadas y depuradas, con coloraciones diversas (desde tonos verdosos a las características rojizo-anaranjadas) y adición frecuente de desgrasantes de medio-gran tamaño.

Cronología: Las diferencias entre los ejemplares del s. -IV y los de la fase de los siglos -III/-II son poco perceptibles, de existir, en el registro actualmente disponible (que suele adolecer de un grado de fragmentación alto). Fue una forma usada de forma continuada desde época púnica hasta al menos el s. -II avanzado, si bien como en el caso de la forma 3.2.2 parece que su fin de vigencia se debió a una paulatina transformación a los nuevos gustos imperantes.

Centros de producción: Torre Alta, Campo del Gayro, El Canal, Gallineras.

Bibliografía: Ruiz y Pérez 1995: 93, fig. 29, 2.

\section{FORMA GDR 4.1.2}

Denominación genérica: lebrillo con asas

Comentario formal: Variante de la forma anterior, con características generales del vaso similares. Sin embargo, este subtipo suele presentar un labio desarrollado, engrosado y considerablemente saliente, 
paredes algo más rectas y la adición de dos o cuatro asas de forma redondeada y sección oval aplanada. La presencia de asas en algunas series de lebrillos, manufacturados coetáneamente a los carentes de ellas, parece plantear la dedicación a funciones distintas de este tipo de recipientes.

Medidas: Diám. Máx.: 36-42 cms. Anch. Labio: 2-3 cms. Alt.: ¿similar al tipo 4.1.1?.

Acabado externo: Similar al subtipo 4.1.1. Ocasionalmente se observan recubrimientos a base de un engobado de barbotina de aceptable espesor.

Características de pasta: Similar al subtipo 4.1.1.

Cronología: Los ejemplares de lebrillos dados a conocer para los ss. -VI/-IV no presentan asas, si bien no es descartable una aparición ocasional de las mismas cuando el destino específico del vaso lo requiriese. Son relativamente frecuentes entre las producciones del alfar de Torre Alta correspondientes al último tercio del s. - III y la primera mitad del -II, siendo difícil establecer su continuidad más allá.

Centros de producción: Torre Alta (escombrera MC-II), Centro Atlántida.

Bibliografía: Sáez 2004.

\section{TIPO 5: PLATOS}

\section{FORMA GDR 5.1.1}

Denominación genérica: plato de pescado

Comentario formal: Tipo de origen ático, abundantemente importado a la península durante los ss. -V/-IV, cuyo perfil y funcionalidad influyó notablemente en los platos de producción gadirita coetáneos. Como parecen indicar los datos preliminares aportados por el alfar isleño de Villa Maruja (Bernal et alii 2003: 49-101), desde comienzos del -IV la influencia formal es ya acusada y probablemente ya hacia mediados-fines de la centuria comiencen a imitarse los prototipos áticos desterrando las tradiciones semitas, si bien se dará la convivencia de ambos tipos durante algún tiempo. Estas primeras imitaciones presentan un pie ya anular y pastas grises-amarronadas oscuras, pero sin embargo carecen de barniz siquiera al interior. Los ejemplares que ahora estudiamos en esta propuesta tipológica, con pies indicados y bordes colgantes poco desarrollados, se presentan de forma clara como la evolución de aquellas primeras imitaciones sin barniz.

Medidas: Diám. Máx.: 17-19 cms. Diám. Base: 6-6,5 cms. Alt. Total: 3-3,5 cms.

Acabado externo: Estos platos suelen presentar un cuidado alisado en toda la superficie y un recubrimiento total de un fino engobe del mismo color que la pasta. No presentan, al contrario que los ejemplares barnizados (Niveau 2003: 46-55), acanaladuras en el borde o alrededor del pocillo central y carenaciones en el pocillo demasiado aristadas. En ocasiones, caso de un par de ejemplares recuperados en superficie en Torre Alta, estos platos fueron barnizados en rojo en el interior y sobre el borde (aplicado a pincel). En el taller de Centro Atlántida han podido ser documentadas algunas piezas fragmentarias torneadas en pastas grises, si bien la falta de un contexto estratigráfico fiable no permite asegurar que correspondan a producciones del s. - III (la impresión genérica sobre las mismas a nivel formal parece remitir a un momento anterior o muy inicial de la centuria).

Características de pasta: Pastas con tonalidades finales oscilantes entre tonos rojizos-anaranjados y amarillento-pajizo, bien depuradas y cubiertas de un fino engobe del color de las propia pasta.

Cronología: Si bien parece que podemos rastrear la producción de estos platos hasta fines del s. -IV, la forma aquí presentada parece encontrar su etapa de auge en los años centrales y la segunda mitad del s. -III, perdurando quizá algún tiempo. Durante esta etapa de los ss. -III/-II convivirá, si bien en menor proporción, con los ejemplares barnizados de la forma Niveau II (2002: 285).

Centros de producción: Torre Alta, ¿Centro Atlántida? ¿Campo del Gayro?.

Bibliografía: inédita. 


\section{TIPO 6: TAPADERAS}

\section{FORMA GDR 6.1.1}

Denominación genérica: tapadera

Comentario formal: Esta forma de tapadera, categoría vascular muy poco conocida dado el exiguo número de hallazgos en ámbito gadirita, representa de forma clara una clase atípica dentro de su género entre lo conocido para otros talleres púnicos centromediterráneos del momento (Guerrero 1995: figs. 3, 6-7 y 11). Se trata de un tipo de tapadera reversible, al estilo de los lécanes griegos, siendo en realidad un plato de borde simple aplanado con pie anular poco desarrollado. Su peculiar morfología permitiría una función multiuso, como cierre probablemente de determinadas formas de ollas o cazuelas y, en su caso, como plato.

Medidas: Diám. Máx.: 21-22 cms. Diám. Base: $8 \mathrm{cms}$. Alt. Total: 4,5 cms.

Acabado externo: Estas tapaderas presentan un acabado homogenizador caracterizado por un tenue engobado del color de la pasta y un cuidado alisado en la zona interna. El pie presenta deficiencias técnicas como su escaso desarrollo y la relativa funcionalidad como pomo de sujeción, quizá fruto de la excepcionalidad de este tipo de apoyos entre las producciones gadiritas del momento.

Características de pasta: Pastas amarillentas depuradas con adición de desgrasante fino micáceo-cuarcítico (esencialmente arena voladera y en ocasiones conchas marinas machacadas), con características propias del taller.

Cronología: Su documentación en el relleno del Horno 4 del taller de Torre Alta y su excepcional morfología parecen apuntar a una manufactura de este tipo acotada al último tercio del s. -III, si bien la escasez de hallazgos impide afirmar con rotundidad los extremos de su periodo de vigencia.

Centros de producción: Torre Alta (documentada en el Horno 4).

Bibliografía: Sáez 2004.

\section{FORMAS GDR 6.2.1 y 6.2.2}

Denominación genérica: tapadera pequeña

Comentario formal: Tapaderas de reducidas dimensiones, no pertenecientes a series estandarizadas producidas en alto número, con bordes simples redondeados o ligeramente aristados (var. 6.2.2) y pomos prominentes. No contamos entre las producciones locales de los ss. -V/-IV con paralelos de estas tapaderas, si bien su carácter «excepcional» no permite valorar las posibles influencias foráneas. Su funcionalidad, en cualquier caso no relacionada con el cierre hermético de las ánforas, puede relacionarse con diversos recipientes de esta tipología (formas 7.2.1, 8.1.1, 12.1.1 o 12.4.1, en variantes cuyo diámetro coincida), si bien es difícil determinar su relación con alguna categoría concreta.

Medidas: Variante 6.2.1: Diám. Máx.: 9,5-10 cms. Diám. Pomo: 4,5-5 cms. Alt. Total: $4 \mathrm{cms}$.

Variante 6.2.2: Diám. Máx.: 9,5-10 cms. Diám. Pomo: $3 \mathrm{cms}$. Alt. Total: 2,5-3 cms.

Acabado externo: Cuidado alisado de las superficies y engobado de barbotina del color de la pasta. En la variante 6.2.1 el torneado es de mayor calidad, mientras la variante 6.2.2 muestra una menor maestría o atención del alfarero, especialmente en el acabado del pomo.

Características de pasta: En la variante 6.2.1 predominan las pastas muy depuradas de coloraciones amarillentas, mientras la variante 6.2.2 presenta pastas menos cuidadas y depuradas con coloraciones rojizas-anaranjadas.

Cronología: Los contextos de hallazgo de las piezas presentadas en nuestra tipología, documentadas en el alfar de Torre Alta, apuntan a una manufactura centrada en el último tercio del s. -III, si bien el torneado más o menos ocasional de estas tapaderas debió prolongarse durante la primera mitad del s. - II. Centros de producción: Torre Alta (escombrera MC-II).

Bibliografía: Sáez 2004. 


\section{TIPO 7: VASOS}

\section{FORMAS GDR 7.1.1, 7.1.2 y 7.2.1}

Denominación genérica: vaso de «perfil en S».

Comentario formal: Los vasos de este tipo se encuentran ya englobados en el repertorio vascular documentado en Cartago en el s. -VIII (Vegas 2000: 1246, fig. 6, 6-7; Niemeyer et alii 2002: 74, fig. 17b), cubiertos parcialmente tanto al interior como al exterior de engobe rojo. Se trata por tanto de una forma con una antigua implantación en los gustos semitas occidentales, lo que parece sugerir que probablemente su origen debamos buscarlo en Oriente. La forma debió tener bastante éxito en Cartago pues su producción local, con cubierta parcial de engobe negro o rojo, perduró al menos hasta los comienzos del s. -VI (Vegas 2002: 153, fig. 2, 18-23), estando menos clara su continuidad y vigencia durante los siglos siguientes. En cuanto a la manufactura gadirita de estos tipos carecemos de datos para la etapa arcaica, pero podemos sospechar que debió tratarse de una forma relativamente usual entre los repertorios vasculares de los talleres coloniales. Apoyando aparentemente esta tesis, las piezas de este tipo más antiguas documentadas en los alfares gadiritas como parte de la producción local pertenecen a fines del s. -VI o comienzos de la centuria siguiente, como ilustra el ejemplo de Sector III Camposoto (Ramón et alii 2004). Durante el s. $-\mathrm{V}$ se fabricaron versiones tanto en cerámica común sin tratamiento como en pastas grises con un cuidado acabado externo, perdurando la manufactura de estos vasos durante el s. - IV en pastas comunes. Las variantes mostradas en nuestra tipología del s. -III pertenecen sin duda a la culminación de esta línea productiva, mostrando líneas más evolucionadas: mayor estilización, carenaciones más suaves, presencia de pequeñas asas en los ejemplares de mayor tamaño, estandarización en dos series de tamaños diferenciados, etc... La producción de estos vasos fue también bastante común en los alfares turdetanos del interior gaditano ${ }^{6}$, usualmente decorados con bandas o cubiertas completas en barniz rojo (Gutiérrez 1999: 26), lo que refleja de nuevo las íntimas relaciones entre ambas vajillas en estos momentos. Por otro lado, se han documentado algunos de estos vasos de tamaño menor (var. 7.1.17.1.2) barnizados totalmente de rojo y con un asa de sección plana, englobados como forma Niveau XII (2003: 81-82) dentro del repertorio de vajilla helenística gadirita del momento7.

Medidas: Variantes 7.1.1 y 7.1.2: Diám. Máx.: 8-10 cms. Diám. Boca: 8,5-10,5 cms. Diám. Base: 4,5-6 cms. Alt. Total: 8-9 cms. Variante 7.2.1: Diám. Máx.: 14,5-17 cms. Diám. Boca: 15-17,5 cms. Diám. Base: $6-8 \mathrm{cms}$. Alt. Total: $12,5-15 \mathrm{cms}$.

Acabado externo: Cuidado variable según la pieza en el alisado superficial, generalmente cubiertos por una capa de engobe del color de la pasta.

Características de pasta: Pastas rosadas a amarillentas muy depuradas con desgrasantes finos a mediabaja frecuencia.

Cronología: Tanto la versión de tamaño normal como los vasos grandes, usualmente monoansados, tienen precedentes más o menos cercanos en las producciones locales ${ }^{8}$ de los ss. -V/-IV. Estos vasos propios del servicio de mesa cotidiano continuaron utilizándose en los hogares gadiritas durante la totalidad del s. - III (produciéndose en ingentes cantidades en la segunda mitad, especialmente del tamaño menor),

6. Y al parecer no de forma exclusiva, pues en los alfares localizados en Pajar de Artillo (Santiponce, Sevilla) se documentaron varios ejemplares decorados con bandas rojas con tipologías similares a las aquí propuestas (Luzón 1973; Ruiz Mata 1998).

7. Nos parece necesario al respecto de estos vasos barnizados, localizados tanto en la bahía gaditana como en el taller de Kouass (Ponsich 1968: lám. XI abajo), realzar las mutuas influencias entre las categorías comunes y barnizadas torneadas en los mismos talleres de forma sincrónica, frente a la injerencia formal de perfiles áticos muy anteriores cronológicamente o etruscos-itálicos (Niveau 2002: 143).

8. También entre ejemplares de probable producción de la costa mediterránea andaluza, como los documentados en un nivel fechable en el s. -IV en Ciavieja (Carrilero y López 1994: 258, fig. 5, 6-7). 
localizándose en pozos de la necrópolis gaditana (Niveau 2004: 18, fig. 15, 6-7), en el poblado de Las Cumbres (Ruiz y Pérez 1995: 92, fig. 28, 5) y en el saladero de Puerto 19 (Gutiérrez 2000: 44, fig. 10). Su manufactura continuó al menos hasta mediados del s. -II (Arteaga et alii 2001: 135, fig. 11, 5), si bien es probable que se produjese una perduración aún mayor para los vasos de tamaño menor.

Centros de producción: Torre Alta.

Bibliografía: Sáez, 2004.

\section{TIPO 8: TINAJAS}

\section{FORMAS GDR 8.1.1 y 8.1.2}

Denominación genérica: tinaja de borde subtriangular

Comentario formal: Recipientes de tendencia piriforme con fondos rehundidos o en ocasiones casi planos y bocas de tamaño medio-reducido con labios de sección triangular ligeramente exvasado al exterior, existiendo una notable variabilidad en cuanto a diámetros y tamaño general del cuerpo. En el caso de la variante 8.1.2, los bordes se presentan pegados a los hombros, con una morfología más sólida y compacta que la variante 8.1.1. Asimismo, los del tipo 8.1.2 presentan una acanaladura simple o doble en los hombros, quizá como indicativo de alguna medida o simplemente como decoración. Este tipo procede de una larga secuencia evolutiva dentro de las producciones gadiritas. Su origen lo encontramos en los pithoi de época arcaica y las jarras mono o biansadas de los ss. -VI/-V, encontrando ya en el $-\mathrm{V}$ avanzado ejemplares policromados sin asas cercanos a los tipos definidos aquí (Ramón et alii 2004: fig. 18). Los hallazgos del alfar de Villa Maruja (Bernal et alii 2003) parecen situar la fijación del tipo en un momento avanzado del -IV o ya en el -III, siendo muy abundantes a partir de mediados de esta centuria9.

Medidas: Diám. Boca: 12-16 cms. Diám. Máx.: 26-30 cms. Diám. Base: 9-12 cms. Ancho borde: 1,52,5 cms. Alt. Total: $35-40 \mathrm{cms}$.

Acabado externo: Ambos subtipos presentan alisados superficiales cuidados, con bordes en ocasiones muy aristados, y engobados superficiales de barbotina del color de la pasta. Con la cautela propia de los escasos ejemplares conocidos, sí podemos señalar el que algunos individuos de la variante 8.1.2 presentan una acanaladura en los hombros y el labio pintado de rojo (tanto al exterior como al interior). Características de pasta: Las pastas, muy depuradas generalmente, presentan coloraciones rosáceas a amarillentas con adición frecuente de desgrasantes finos (mica, cuarcitas y conchas machacadas...).

Cronología: Será un tipo de gran aceptación hasta la etapa imperial de Gades, usada en estos últimos pasos de forma principal como recipiente funerario para las numerosas cremaciones de la etapa (Gordillo 1987; López 2003: figs. 1-4). La forma presentada en nuestra tipología se manufacturó en los alfares gadiritas sin grandes cambios en el esquema formal a partir de prototipos del s. -IV durante la totalidad del s. -III y al menos la primera mitad del s. -II (Arteaga et alii 2001: 134, fig. 10, 2), derivando entonces a nuevas variantes con un cuello cada vez más definido.

Centros de producción: Torre Alta, Campo del Gayro, Huerta del Contrabandista, El Canal, Centro Atlántida.

Bibliografía: Sáez 2004.

9. Un ejemplar fragmentario de esta forma fue documentado en el Estrato 24 del corte 5 de las antiguas excavaciones de M. Tarradell en Lixus (Belén et alii 2000: 105, fig. 14, 601). 


\section{TIPO 9: VASO-TINAJA}

\section{FORMA GDR 9.1.1}

Denominación genérica: pequeña tinaja abierta

Comentario formal: Forma de aparente parentesco turdetano propia de funciones de almacenaje cotidiano, fue fabricada en un número reducido en los alfares gadiritas. Se trata de formas intermedias entre los vasos del tipo 7.2.1 y las tinajas del tipo 8.1.1, con diámetros de boca amplios, bordes subtriangulares exvasados y fondos rehundidos. Se produjo en un número considerablemente reducido en los alfares gadiritas.

Medidas: Diám. Boca: 14-16 cms. Diám. Máx.: 18-19 cms. Diám. Base: 7-8 cms. Alt. Total: 15-17 cms. Acabado externo: Los ejemplares turdetanos coetáneos presentan un buen acabado con cubierta de engobe externa bruñida (Martín Ruiz 1995: 58, fig. 27). Sin embargo, los manufacturados en talleres gadiritas no tienen cubierta policroma ni bruñido de las superficies, si bien presentan alisados uniformes y engobados de espesor variable del color de la pasta.

Características de pasta: Arcillas comunes del área, de coloraciones predominantemente amarillentas a rosáceas, bien depuradas y con frecuente adición del elenco de desgrasantes propio de estos alfares.

Cronología: Si bien con topes cronológicos indefinidos aún en sus extremos, su manufactura está documentada para la segunda mitad del s. -III y los inicios del -II.

Centros de producción: Torre Alta (hallazgos fragmentarios en Hornos 4 y 5).

Bibliografía: Ruiz y Pérez 1995: 91, fig. 27, 14.

\section{TIPO 10: JARRAS}

\section{FORMA GDR 10.1.1}

Denominación genérica: gran jarra monoansada

Comentario formal: Jarra de notables dimensiones, claramente emparentada a nivel formal con las tinajas sin asas de la forma 8.1.1, documentada por el momento sólo a nivel fragmentario entre las producciones del taller de Torre Alta. Se define por un cuerpo piriforme con fondo rehundido indiferenciado y un borde simple presumiblemente trilobulado (si bien es factible pensar en la manufactura sincrónica de piezas con borde circular simple). El asa, sobreelevada por encima de la boca, tiene una sección irregular bilobulada de tendencia general estrecha, adosándose al cuerpo de forma suave en los hombros. Esta serie de jarras grandes monoansadas cuenta con paralelos alejados formal y cronológicamente entre las producciones locales del s. -V (Ramón et alii 2004), si bien no puede establecerse claramente la relación directa entre ambos tipos. Sin embargo, su pertenencia a la tradición local es perceptible a tenor de las similitudes con las jarras de pequeño formato y las tinajas de la forma 8.1.1. Sí es necesario señalar la dificultad de distinguir estas jarras en estado fragmentario de otras formas locales (especialmente las series 8-9) debido a las acusadas similitudes generales, por lo que es actualmente difícil valorar la importancia cuantitativa de su manufactura. Formalmente parecen poder asimilarse a una variante de la forma Cintas 140-145 (Guerrero 1999b: 190, fig. 69) o de jarras ebusitanas contemporáneas (Rodero 1980: 15, fig. 1.15a), si bien quizá sólo podamos culpar a las influencias foráneas en este caso de la pervivencia de dos series con tamaños distintos de jarras más que de la propia morfología del vaso.

Medidas: Diám. Boca: ¿8 cms.? Diám. Máx.: 21-22 cms. Diám. Base: 8 cms. Alt. Total: ¿30-35 cms? Acabado externo: Alisados cuidados, con una adición de las asas bien terminada y disimulada, y engobados superficiales de barbotina de colores predominantemente ocres-amarillentos. Los ejemplares conocidos no presentan decoración policroma.

Características de pasta: Arcillas bien depuradas, con adición frecuente de desgrasante fino, predominando las coloraciones anaranjadas si bien también existen ejemplares con presencia mixta rosácea-anaranjada. 
Cronología: Su posición como eslabón más evolucionado de una forma local con tradición en Gadir hace difícil situar el inicio de la manufactura de perfiles como el propuesto en nuestra tipología. Puede asegurarse un inicio hacia mediados del s. -III, perdurando al menos hasta los inicios del s. - II.

Centros de producción: Torre Alta, ¿Campo del Gayro?, ¿C/ Luis Milena?.

Bibliografía: Sáez 2004.

\section{FORMA GDR 10.2.1}

Denominación genérica: jarra cilíndrica de asa de sección aplanada.

Comentario formal: Tipo cuyo origen y evolución se asemejan a lo descrito para el anterior, configurado en la versión que aquí presentamos hacia mediados del s. - III. Se trata de jarras de pequeñas-medianas dimensiones propias del servicio de mesa cotidiano de cuerpo con tendencia cilindroide con cierto abombamiento en la parte central, con bases diferenciadas y pies indicados o de galleta. Los bordes son siempre simples sin vertedor, partiendo de él una corta asa que se adosa al cuerpo en la zona de arranque del cuello. Jarras similares, sin duda inspiradas en los olpes griegos coetáneos fueron fabricadas en Gadir al menos desde el s. -V ((Ramón et alii 2004)), si bien la morfología de los prototipos del s. -III como el ahora estudiado denota una gran evolución de las características de aquellas. Se trata, según los datos actuales, de un modelo también derivado internamente en los alfares gadiritas pues ni los modelos ebusitanos sincrónicos (especialmente la forma Eb. 23b y afines, $C f$. Guerrero 1999b: 37, fig. 61) ni otras producciones del Estrecho como las jarras de la necrópolis de Puente de Noy (tipos II-III sobre todo, $C f$. Huertas y Molina 1983: 499, fig. 4) parecen haber influido decisivamente en la configuración formal de estas jarras gadiritas. Modelos similares al propuesto los encontramos en contextos del s. - III en zonas muy íntimamente relacionadas con Gadir como la instalación rural jerezana de Cerro Naranja (González 1987: 94, fig. 5, 22) o el alfar de Kouass (Ponsich 1968: lám. XIV arriba dcha.).

Medidas: Diám. Boca: 3-4 cms. Diám. Máx.: 7,5-9 cms. Diám. Base: 5-6 cms. Alt. Total: 20-21 cms. Acabado externo: Normalmente presentan un aceptable alisado superficial y un engobado con barbotina del color de la pasta de grosor variable. Algunos individuos del alfar de Campo del Gayro presentan una acanaladura simple en la parte baja del cuerpo, cercana a la base.

Características de pasta: Arcillas rojizas-anaranjadas de fractura irregular con adición de desgrasantes finos-medios micáceos, cuarcíticos y orgánicos (conchas) a media frecuencia.

Cronología: Como ya enunciamos anteriormente, parece que la forma definida en nuestra tipología se configuró como tal hacia mediados del s. - III o poco antes, perdurando su torneado al menos durante la primera mitad del -II.

Centros de producción: Torre Alta, Campo del Gayro.

Bibliografía: inédita.

\section{FORMA GDR 10.3.1}

Denominación genérica: jarrita de boca trilobulada

Comentario formal: Forma cerrada de reducido tamaño directamente emparentada con las jarritas de la forma 10.4.0, fue fabricada con diversas variantes debidas a la diversidad de alfareros de forma paralela. Los hallazgos de Torre Alta expuestos en el museo isleño evidencian asimismo una manufactura coetánea de jarritas de este tipo en al menos dos tamaños, si bien ambas series mantienen el esquema general y sus dimensiones difieren en la mayor parte de casos en pocos centímetros de altura total. La boca trilobulada, y en especial el pico vertedor, presentan según el ejemplar un desarrollo diferencial pues mientras algunos ejemplares poseen picos muy aristados otros tienen labios que sólo han sido tenuemente modificados como vertedores. El asa, de sección pseudo-circular, se adosa al labio y al cuerpo a la altura del inicio del cuello. Este tipo de jarrita, si bien no enteramente desconocida en la tradición local, 
encuentra paralelos casi exactos en producciones ibicencas de la época (Rodero 1980: 54-55, fig. 14, 3-4), por lo que parece tratarse en conjunción con la adopción de la forma 10.4.1 de una nueva muestra de la influencia pitiusa sobre el repertorio común gadirita en momentos avanzados del s. -III.

Medidas: Diám. Boca: 3-3,5 cms. Diám. Máx: 5,5-6 cms. Diám base: 3-3,5 cms. Alt. Total: 10-10,5 cms.

Acabado externo: Buen alisado de las superficies y engobado de espesor variable del color de la pasta, no conociéndose ejemplares con decoración policroma.

Características de pasta: Arcillas muy depuradas de tonos rosáceos-anaranjados con adición a mediabaja frecuencia de desgrasantes finos (mica, arena fina, cuarcita, conchas o cerámica triturada, etc...).

Cronología: La manufactura a gran escala de estas jarritas puede situarse en el último tercio del s. -III y los inicios del -II, surgiendo probablemente algo antes y perdurando quizá hacia mediados del s. - II, en consonancia con la continuidad de muchas de las formas de esta tipología.

Centros de producción: Torre Alta.

Bibliografía: Sáez 2004.

\section{FORMAS GDR 10.4.1 y 10.4.2}

Denominación genérica: jarrita piriforme con asa de sección circular.

Comentario formal: Se trata de jarras de pequeño formato, con pies indicados o de galleta y cuerpos de tendencia globular con cuellos cilíndricos, con un sistema de sujeción simple consistente en un asa de sección circular adosada al cuerpo en la zona de diámetro máximo y al borde. Siguiendo a V. M. Guerrero (1999b: 35 y 40), podemos decir que se trata de una nueva muestra de la influencia centromediterránea en la producción cerámica de Gadir en estos momentos. Estas jarritas, producidas en Ibiza (forma Eb. 13), en Cartago (forma Cintas 110/111) y en otros puntos del Mediterráneo Central (Guerrero 1999b: 40), fueron también «versionadas» en los alfares gadiritas. La variante 10.4.1, más afín a los prototipos centromediterráneos, fue de introducción más tardía (su fabricación no parece ser anterior al segundo cuarto del s. - III), siendo realmente abundantes a partir del último tercio de la misma centuria. La variante 10.4.2, formalmente también emparentada con algunas jarras-botellas turdetanas (Gutiérrez 1999: 30), parece tener por el contrario un origen más remoto entre las producciones locales del s. -IV del alfar de Villa Maruja (Bernal et alii 2003: 63, fig. 15, 8).

Medidas: Diám. Boca: 3-4 cms. Diám. Máx.: 6-7 cms (var. 10.4.1) y 8,5-9,5 cms (var. 10.4.2). Diám. Base: 3,5-5 cms. Alt. Total: 9-9,5 (var. 10.4.1) o 10-11 (var. 10.4.2).

Acabado externo: Alisado superficial cuidado y engobado de espesor variable del color de la pasta. Las zonas de inserción de las asas suelen presentar un buen acabado, con alisado de los sobrantes, disimulados tanto en el cuerpo como en la unión con el borde.

Características de pasta: Pastas rosadas-rojizas o amarillentas típicas de la zona, de fractura variable, bien depuradas y con adición de desgrasante fino micáceo-cuarcítico.

Cronología: La manufactura de la variante 10.4.2, quizá influida por modelos turdetanos además de centromediterráneos, parece poder rastrearse hasta el s. -IV, continuando durante el s. -III y los inicios del siguiente. Sin embargo, la variante 10.4.1 está ausente en contextos anteriores a mediados del -III, siendo frecuente en contextos datables en los últimos compases de dicho siglo (en Las Cumbres; Ruiz y Pérez 1995: 92, fig. 28, 6) y en depósitos de la primera mitad del s. -II (caso de algunos niveles de las escombreras de 1995 del alfar de Torre Alta). De cualquier forma, el fin de la producción de ambas series se encuentra aún por definir totalmente.

Centros de producción: Torre Alta, Campo del Gayro (var. 10.4.1), Huerta del Contrabandista (var. 10.4.1).

Bibliografía: inédita. 


\section{TIPO 11: CAZUELAS}

\section{FORMA GDR 11.1.1}

Denominación genérica: cazuela

Comentario formal: Si bien los bordes de ollas-cazuelas con solero para el apoyo de la tapadera podemos rastrearlos hasta etapas muy anteriores en Oriente, con ejemplares de ollas de los strata X-XIII de Tiro (Bikai 1978: pl. XXXIII-XXXVII) o del estrato G de Sarepta (Pritchard 1978: 80), nuestra forma parece derivar de forma más o menos directa de las cazuelas gadiritas de los ss. -VI/-V junto a influencias foráneas posiblemente ebusitanas ${ }^{10}$ (una buena muestra de comparación en Gómez y Gurrea 1985 y Guerrero 1995: figs. 3-4), o en un marco más general, centromediterráneas (Guerrero 1995: figs. 10-11). Este tipo, con una notable rectitud de sus paredes y una marcada tendencia a alcanzar el diámetro máximo en la zona del labio externo, parece presentarse de nuevo como un indicio de la entrada de nuevas corrientes formales-funcionales durante el s. - III en los alfares de Gadir ligadas especialmente al tráfico comercial con Ibiza y al trasiego de gentes del Mediterráneo Central tras el desembarco bárcida. Medidas: Diám. Máx.: 35-40 cms. Diám. Solero int.: 31-34 cms. Diám. Carena cuerpo: 29-31 cms. Alt. Total: ¿9-10 cms?.

Acabado externo: El acabado de estas piezas suele corresponderse con un engobado superficial en ocasiones relativamente espeso de un color similar a la pasta, si bien en numerosas ocasiones la falta de un alisado cuidado y el tamaño notable de algunos desgrasantes dan un aspecto un tanto tosco a esta categoría. Existen sin embargo otras piezas con pastas más depuradas que adquieren en la cocción tonos amarillentos habituales en las restantes categorías comunes no dedicadas a la cocción o cocinado de alimentos. Entre estas últimas podemos situar algunas piezas decoradas en el borde del solero externo con ovas impresas formando un motivo continuo a lo largo de todo el labio ${ }^{11}$. Asimismo, se puede asegurar que al igual que los prototipos gadiritas de centurias anteriores (atestiguados al menos desde inicios del s. -V) y que sus coetáneos centromediterráneos, este tipo de cazuelas presentaban dos asas horizontales, en ocasiones de considerables dimensiones, normalmente unidas casi totalmente al cuerpo y colocadas justo bajo el labio sin llegar a sobrepasarlo en altura.

Características de pasta: Existen versiones de estas cazuelas en dos tipos de pastas distintas, lo que parece mostrar una planificación en el futuro uso que sería dado a cada clase. Por un lado, encontramos pastas poco depuradas con tonalidades marrones-grises con adición de numeroso desgrasante micáceo y cuarcítico de mediano-pequeño tamaño a media frecuencia que denota una inclusión segura de estas piezas entre las destinadas a estar expuestas al fuego. Por otro lado, un número notablemente más reducido de estas cazuelas presenta pastas comunes propias de las cerámicas de uso doméstico o almacenaje, en ocasiones verdosas (Niveau 2004: 16), cuya finalidad nos es desconocida al aparentemente no ser aptas para su uso en la elaboración de alimentos al fuego. Su aparición en contextos como la necrópolis gaditana (idem. 15-16, fig. 12) quizá apunte a una fabricación ex profeso de algunos ejemplares con este destino.

10. Resulta muy interesante a este respecto la similitud con materiales coetáneos ibicencos como las producciones del taller alfarero FE-13 (Ramón 1997: figs. 50-53).

11. Piezas de estas características en contextos del s. - III avanzado han sido documentadas en pozos de la necrópolis gaditana, nombradas como centromediterráneas (Niveau 2001: 207 y 212, figs. 11 y 14; Niveau 2004: 16), junto a individuos de producción local de las formas 3.1.1, 7, 8.1.1 y 12.3.1 de nuestra tipología. Las diferencias de pastas y engobes nombradas por esta autora parecen corresponder con la diversidad de talleres ubicados en la periferia insular isleña de Gadir más que con un origen foráneo de estas piezas, documentadas tanto en Torre Alta como en el Cerro de la Batería. La decoración de ovas impresas no es por otro lado una decoración extraña a las producciones locales del momento (Niveau 2004: 16) pues además de en estas cazuelas la encontramos en imitaciones locales parcialmente barnizadas de rojo de platos inspirados en piezas propias de los talleres itálicos de Teano (Niveau 2004b) formando parte de su profusa decoración estampada, manufacturadas en Torre Alta. 
Cronología: Se trata de una forma relativamente común entre las producciones de los alfares gadiritas, especialmente a partir de la II Guerra Púnica, mostrando innumerables variantes formales según la procedencia pero respetando el esquema aquí propuesto. La vigencia de éste puede alargarse al menos hasta las postrimerías del s. - II, momento en que el uso e imitación local de formas latinas como las cazuelas Vegas 14 (detectada por ejemplo en Pery Junquera, $c f$. González et alii 2002) parecen ir sustituyendo de forma definitiva las de tradición púnica. El arco cronológico más ajustado a la forma ahora estudiada correspondería a la segunda mitad del-III y la primera mitad del -II, con topes aún imprecisos en ambos extremos.

Centros de producción: Forma realizada en la totalidad de los alfares gadiritas conocidos.

Bibliografía: Sáez 2004.

\section{FORMA GDR 11.2.1}

Denominación genérica: olla con borde digitado

Comentario formal: Tipo documentado en un estado demasiado fragmentario como para definirlo formalmente sin entrar en el terreno de la mera especulación. La ausencia de otros paralelos publicados hace que el borde documentado en una de las escombreras del taller de Torre Alta sea el único testimonio conocido de esta clase de ollas, similares a las del tipo 12.3.0, con la salvedad de la decoración de digitaciones en el solero que les es exclusiva. Debido a las razones ya comentadas pocas valoraciones podemos entrar a realizar en cuanto al origen formal de esta clase o de su difusión, por lo que deberemos esperar a que futuros hallazgos nos ayuden a definir estas cuestiones.

Medidas: Diám. Boca: 20,5 cms.

Acabado externo: Engobado externo de grosor destacable de barbotina, con un cuidado de las superficies irregular ya que algunos desgrasantes de tamaño medio han aflorado a la superficie del vaso. La decoración del solero se realizó apretándolo a intervalos regulares.

Características de pasta: Pastas oscuras marrones-grisáceas no muy depuradas con adición frecuente de desgrasantes de tamaño pequeño-medio (especialmente micáceos y arena).

Cronología: Dado el escaso conocimiento que poseemos sobre este tipo sólo podemos afirmar su presencia en contextos del último tercio del s. -III.

Centros de producción: Torre Alta.

Bibliografía: Sáez 2004.

\section{TIPO 12: OLLAS}

FORMA GDR 12.1.1

Denominación genérica: olla globular de borde exvasado

Comentario formal: Tipo documentado en estado fragmentario en el horno 5 del alfar de Torre Alta, lo que impide aún su total descripción formal. Se trata de ollas de labios vueltos al exterior y levemente engrosados, con un cuerpo con tendencia globular. Desconocemos las características del tercio inferior de esta categoría, si bien los paralelos aportados por los tipos 12.2.1 y 12.3.1 apuntan a una base plana o ligeramente rehundida. Los ejemplares conocidos no presentan indicios de elementos de sujeción alguna, al contrario de lo habitual en los repertorios centromediterráneos coetáneos (Guerrero 1995; 1999a; Gómez y Gurrea 1985), si bien no es descartable que otras series los poseyeran. Su origen no puede ser clarificado con rotundidad, si bien puede emparentarse con algunas ollas de producción local del s. -V (Ramón et alii 2004), aunque los tipos intermedios del s. -IV no están aún bien caracterizados. Medidas: Diám. Boca: 12-14 cms. Diám. Máx: 23-25 cms. Alt. Total: ¿?

Acabado externo: Buen alisado de las superficies y torneado regular y cuidado, presentando las piezas un engobado de barbotina de espesor variable. 
Características de pasta: Se dan dos variantes, con ejemplares con pastas de "tipo cocina" de tonos marronáceos con abundantes desgrasantes de tamaño pequeño-medio y por otro lado con individuos con arcillas depuradas propias de los tipos comunes no destinados al fuego, de tonos rosáceos-anaranjados con desgrasantes finos abundantes. De nuevo, esta dualidad de tratamientos puede estar indicando una manufactura deliberada de dos series con funcionalidades distintas o la existencia de múltiples talleres. Cronología: El escaso conocimiento actual sobre esta forma sólo permite enmarcarla en el último tercio del s. -III y los inicios del -II, si bien tanto su inicio como su definitivo abandono han de ser corroborados por futuros hallazgos.

Centros de producción: Torre Alta (Horno 5).

Bibliografía: Sáez 2004.

\section{FORMA GDR 12.2.1}

Denominación genérica: olla de borde exvasado y fondo rehundido

Comentario formal: Recipientes de cocina o "de fuego" estrechamente emparentados con la forma anterior, se trata de vasos con borde engrosado vuelto al exterior alcanzando un diámetro de boca considerable, cuerpo de tendencia piriforme y fondo de pie indicado ligeramente rehundido. Se trata de un estadio evolucionado de ollas ya conocidas en el ámbito gadirita desde al menos el s. -VI (Ruiz 1997: 362 , fig. 7, 1-8) dentro de las producciones locales de sus alfares (Ramón et alii 2004). Si los ejemplares del los ss. $-\mathrm{VI} / \mathrm{-V}$ presentan acanaladuras en los hombros y una mayor tendencia a cuerpos globulares (Ruiz 1997: fig. 7, 6), ya en el s. -III los individuos de esta clase han perdido cualquier tipo de decoración y sus tercios inferiores presentan una tendencia a estilizarse. Se trata por tanto de una forma de tradición local, emparentada con ollas-tinajas del mundo turdetano, en plena adaptación a los nuevos gustos del momento.

Medidas: Diám. Boca: 16-18 cms. Diám Máx.: 24-25 cms. Diám. Base: 11-12 cms. Alt. Total: $22-23 \mathrm{cms}$.

Acabado externo: Similar al de las piezas del tipo 12.1.1.

Características de pasta: Características similares al tipo 12.1.1, con dos series diferenciadas.

Cronología: Su presencia en los niveles del s. -III del poblado de Las Cumbres (Ruiz y Pérez 1995: 93, fig. 29, 1), en asentamientos de la campiña sincrónicos como el Cerro Naranja (González 1987: 93, fig. 4, 17) o entre las producciones locales del alfar de Torre Alta correspondientes al último tercio del siglo (Sáez 2004), apuntan a una manufactura mayoritaria de este tipo en desde el último tercio de dicha centuria, perdurando probablemente durante la primera mitad del s. -II.

Centros de producción: Torre Alta.

Bibliografía: Ruiz y Pérez 1995: 93, fig. 29, 1.

\section{FORMAS GDR 12.3.1 y 12.3.2}

Denominación genérica: olla

Comentario formal: Se trata del tipo de olla predominantemente torneada en los talleres gadiritas durante la segunda mitad del s. -III y la primera del -II, caracterizándose por un borde subtriangular de extremos redondeados a modo de solero, un cuello corto y ancho, un amplio diámetro de boca, un cuerpo de tendencia globular y un fondo con pie indicado y levemente rehundido al interior. Las pertenecientes a la variante 12.3.2, además de presentar por lo general diámetros y medidas totales algo menores, se caracterizan por un borde casi plano y saliente y por una carenación en la transición a la panza más acusada. Es una forma de recipiente de fuego característica del repertorio de tradición gadirita del momento, careciendo las vajillas ibicencas (Gómez y Gurrea 1985) o púnicas centromediterráneas 
(Guerrero 1995 y 1999a-b) de tipos de ollas formalmente aproximados a estos ejemplares gadiritas. Si bien no conocemos por el momento con precisión los individuos del s. - IV, ollas formalmente predecesoras de estas del tipo 12.3.0 podemos encontrarlas (con diferencias como la presencia de acanaladuras múltiples horizontales) en los niveles del s. -V del alfar de Sector III Camposoto (Ramón et alii 2004). Cabe señalar por otro lado que los ejemplares conocidos no portan las características asas horizontales propias de este tipo de recipientes, si bien no es descartable su documentación en nuevos talleres.

Medidas: Diám. Boca: 14-16 cms. Diám. Máx.: 23-26 cms. Diám. Base: 10-11 cms. Alt. Total: 19-21 cms.

Acabado externo: Superficies habitualmente alisadas poco o nada, encontrando frecuentemente desgrasantes de tamaño medio en la superficie de las ollas, a pesar del la espesa cubierta de barbotina externa que presentan.

Características de pasta: Las pastas presentan una escasa depuración, adquiriendo normalmente tonos rojos intensos o marrones-grisáceos. La fractura es irregular, siendo muy frecuentes los desgrasantes refractarios de tamaño pequeño o medio.

Cronología: La presencia cuantitativa de estas ollas dentro del espectro de producciones locales destinadas al menaje de cocina en los alfares isleños es notable en la fase de la segunda mitad del s. $-\mathrm{III}^{12}$, perdurando la manufactura de algunas variantes al menos del tipo 12.3.1 durante la primera mitad del s. -II (Arteaga et alii 2001: 133-134, figs. 5, 3 y 10, 4). Es probable que gradualmente fueran desplazadas por la irrupción de ollas con solero de tipo helenístico centromediterráneo (Gómez y Gurrea 1985: fig. 5) durante el s. -II avanzado, no llegando probablemente a fines de la centuria.

Centros de producción: Torre Alta, Campo del Gayro, Huerta del Contrabandista.

Bibliografía: Sáez 2004.

\section{FORMA GDR 12.4.1}

Denominación genérica: olla pequeña carenada

Comentario formal: Tipo similar al anterior en el esquema formal general, si bien diferenciado esencialmente en la reducción de las medidas y el estrechamiento de la boca y el cuello. Aunque reiterando la aparente excepcionalidad del grupo 12.3.0/12.4.1 gadirita, sí resulta por otro lado conocido entre los repertorios de ollas centromediterráneos, y en especial ebusitanos, la convivencia de series de ollas de tamaño normal-grande con otras más reducidas (varios ejemplos de tipología diversa en Gómez y Gurrea 1985). Este parece haber sido el papel de estas pequeñas ollas de tendencia piriforme y posiblemente de fondo aplanado, destinadas a la cocción de cantidades menores en los hogares gadiritas.

Medidas: Diám. Boca: $11 \mathrm{cms}$. Diám. Máx.: $14 \mathrm{cms}$. Alt. Total: ¿11-13 cms?.

Acabado externo: Similar al documentado sobre piezas del tipo 12.3.0.

Características de pasta: Arcillas y depuración similar a la forma anterior, si bien predominan la tonalidades rojizas sobre las marronáceas.

Cronología: Topes análogos a los señalados para el tipo 12.3.0.

Centros de producción: Torre Alta.

Bibliografía: Sáez 2004.

12. Un fragmento de borde de una de estas ollas, clasificada como producto centromediterráneo, fue documentada en las excavaciones de un contexto de fines del s. -III en la Plz. de San Ginés de Cartagena (Martín 1998: 22, lám. VIII, 4), correspondiendo por su tipo de borde al taller de Campo del Gayro. Es probable que algunas de las cazuelas y ollas de borde con solero correspondan también a producciones gadiritas de la forma 11.1.1 y afines. 


\section{TIPO 13: FUSAYOLAS}

\section{FORMA GDR 13.1.1}

Denominación genérica: fusayola troncocónica.

Comentario formal: Piezas de reducido tamaño, generalmente tronco-cónicas o bi-troncocónicas, con perforación central longitudinal realizada con un elemento duro. Su presencia en talleres locales de época púnica no ha sido documentada aún, por lo que los ejemplares ahora estudiados de la segunda mitad del s. - III y los inicios del -II no encuentran aparentemente acomodo en la tradición local, si bien este extremo habrá de aclararse con la finalización de los estudios en curso de varias alfarerías. Este tipo de fusayolas, relacionadas con las actividades textiles, son bien conocidas en el ámbito indígena (Castro 1980), si bien es difícil en base a los pocos datos disponibles establecer una relación o influencia sobre la manufactura gadirita. Los ejemplares locales conocidos encajan en las formas 40-42 y 45 de la tipología de las fusayolas ibéricas establecida por Martínez y Castellano (1995: 534), no diferenciándose sustancialmente de los ejemplares indígenas. La manufactura textil en Gadir es una cuestión aún por investigar pero la fabricación local de este tipo de fusayolas parece apuntar a una cierta importancia de las misma al menos durante el s. -III.

Medidas: Diám. Máx.: 3-4 cms. Alt. Total: 2-3 cms. Ancho orificio: 0,2-0,5 cms.

Acabado externo: Al igual que en otras categorías presentadas en esta tipología, existen dos tratamientos para individuos del mismo tipo, lo que parece fruto de la distinta pericia de los alfareros y de la existencia de una manufactura diversificada en numerosos talleres. En el caso de las fusayolas, mientras unas son de una regularidad formal notable con alisados superficiales cuidados y perforaciones uniformes y centradas, otras presentas superficies rugosas y proporciones desiguales en cuanto a su forma geométrica se refiere.

Características de pasta: En relación con lo dicho para el acabado de las piezas, mientras algunas muestran arcillas muy depuradas con desgrasantes arenosos muy finos de tonos rosáceos-amarillentos, otras presentan pastas poco decantadas con desgrasantes en ocasiones incluso de tamaño considerable dadas las reducidas dimensiones de las pesas.

Cronología: Nos es imposible por el momento mantener un origen en la tradición local para esta forma, por lo cual si nos ceñimos a los hallazgos conocidos debemos datarlas en la segunda mitad del s. -III y la primera mitad del -II, lo cual no es óbice (dado el estado embrionario de la investigación) para ampliar estos topes en un futuro.

Centros de producción: Torre Alta.

Bibliografía: Sáez 2004.

\section{TIPO 14: PESAS}

\section{FORMA GDR 14.1.1}

Denominación genérica: pesa cilíndrica

Comentario formal: Pesas de dimensiones más reducidas que las del tipo siguiente, de cuerpo cilíndrico perforado longitudinalmente. El origen formal de estas pesas podemos encontrarlo entre las producciones locales de los ss. -VI/-V de alfares como Sector III Camposoto (Ramón et alii 2004), siendo en la etapa tardopúnica muy abundantes en directa relación con las actividades pesqueras.

Medidas: Diám. Máx.: 3-5 cms. Diám. Orificio: 1-1,5 cms. Long. Total: 6-8 cms.

Acabado externo: Normalmente no demasiado cuidado, dada su manufactura en serie en número considerable. Mientras algunos ejemplares muestran una notable proporcionalidad y regularidad en sus dimensiones, otros han recibido una menor atención, presentando paredes más irregulares o perforaciones 
notablemente descentradas. En ocasiones los desgrasantes se encuentran en la superficie de las pesas fruto de un alisado defectuoso. Aunque con excepciones, es común la falta de engobado final de estas piezas, sobre las cuales no se ha documentado decoración policroma o incisa.

Características de pasta: Pastas poco depuradas y decantadas, con coloraciones rojizas, rosáceas o amarillentas, con adición de los desgrasantes habituales de tamaño pequeño-medio.

Cronología: Producidas en talleres gadiritas de forma generalizada al menos desde el s. $-\mathrm{V}$ sin cambios aparentes en su morfología, su vigencia continuó durante el s. -III y buena parte del -II. La sencillez de su manufactura y esquema formal sin duda propició una continuidad de su fabricación hasta enlazar con la época romana avanzada.

Centros de producción: Torre Alta.

Bibliografía: Sáez 2004.

\section{FORMA GDR 14.2.1}

Denominación genérica: pesa circular

Comentario formal: Se trata de elementos de uso artesanal de forma circular aplanada con una perforación central de grueso variable realizada con un punzón duro pre-cocción (en ocasiones con el dedo). Este tipo de pesas fue manufacturada en talleres gadiritas desde al menos el s. $-\mathrm{V}$, según evidencian los numerosos hallazgos del alfar del Sector III Camposoto (Ramón et alii 2004), continuando al parecer su fabricación al parecer hasta el s. -III. Este tipo de pesas no es desconocido tampoco en Cartago, donde han sido exhumadas en buen número (Lancel y Thuillier 1979: 203, figs. 26, 40 y 71; Thuillier 1982: 73, fig. 85, 34; Lancel 1982: 108 y 138, fig. 128, 12, 16 y 19 y fig. 174a) en niveles sincrónicos a la etapa de producción gadirita ${ }^{13}$. Es difícil por tanto asignar un origen exclusivamente local a estas piezas, pues bien pudieron ser ejemplares centromediterráneos los que inspiraron los primeros de factura gadirita. No menos dificultoso se muestra el análisis funcional de estas pesas, al menos de buena parte de ellas: en Cartago han sido relacionadas recientemente con las redes de pesca (Donati 1997: 23) y un fin artesanal similar parece que fue el que tuvieron la mayor parte de ejemplares gadiritas. Cabe realizar una excepción con algunas piezas de factura cuidada y dimensiones muy regulares documentadas en el taller de Villa Maruja (Bernal et alii 2003: 55 y 73, figs. 7 y 25), que bien podríamos relacionar con ponderales. El número de estas pesas circulares es reducido en niveles del s. -III, posiblemente por su sustitución gradual por las de la forma 14.1.1, proceso agudizado en esta centuria y sobre todo en su segunda mitad. Medidas: Diám. Máx.: 14-16 cms. Diám. Orificio: 1-1,5 cms. Anch.: 2,5-3,5 cms.

Acabado externo: Irregular según la pieza, con alisados cuidados en unas y superficies rugosas en otras. Suelen presentar un engobado de barbotina del color de la pasta.

Características de pasta: Pastas típicas de la zona, preferentemente rojizas-rosáceas, con adición frecuente de desgrasantes finos-medios.

Cronología: Atendiendo a los precedentes locales comentados anteriormente, debemos suponer una continuidad de la producción durante el s. -III, no pudiendo precisarse su continuidad más allá de los inicios del s. - II.

Centros de producción: Torre Alta.

Bibliografía: Sáez 2004.

13. También son relativamente abundantes, con tipologías y acabados en muchos casos divergentes, en poblados ibéricos peninsulares (Castro 1985), relacionándose en la mayor parte de los casos con actividades pesqueras como pesas para redes.

ISSN: 1133-4525 ISSN-e: 2255-3924

SPAL 14 (2005)

http://dx.doi.org/10.12795/spal.2005.i14.06 


\section{VALORACIONES Y PERSPECTIVAS DE LA INVESTIGACIÓN}

Una de las principales conclusiones que podemos extraer del análisis del repertorio formal que proponemos ha de ser sin duda su configuración en base a la conjunción de la tradición local-regional y de una creciente influencia formal centromediterránea percibida con claridad desde el s. - IV. Esta confluencia de tendencias formales e innovaciones dio lugar a un repertorio variado si bien no demasiado amplio, con escasa presencia cuantitativa de elementos con decoración polícroma, que cubrían la mayor parte de necesidades cotidianas de los hogares gadiritas en lo tocante a la preparación y cocinado de alimentos y al servicio de mesa (para lo cual habrían de conjugarse con piezas propias del repertorio barnizado de rojo).

Por un lado, debemos destacar la influencia o parentesco con las producciones turdetanas: como puede advertirse de un análisis superficial de las formas examinadas en nuestra tipología, uno de los datos más relevantes es la aparente continuidad tradicional en las formas desde al menos el s. -VI hasta época tardopúnica avanzada. Si bien nuestra propuesta tipológica no es más que un primer acercamiento a la realidad arqueológica de estas categorías vasculares durante un relativamente corto periodo de tiempo nos parece que no podemos dudar ya más en la diferenciación entre las cerámicas del repertorio turdetano indígena y las manufacturadas en talleres de tradición fenicia gadiritas, pese a la evidente interacción entre ambas esferas tipológicas. Las decoraciones pintadas, tenidas hasta el momento como elemento diferenciador principal (Niveau 2004: 14, nota 36) no pueden ya considerarse como tal pues sólo en el caso de la época tratada ahora las formas 1.2.0, 3.2.0, 8 y 10.2.1 presentan en muchos casos decoraciones en rojo a bandas. No cabe duda de las deudas mutuas en cuanto a préstamos formales y funcionales de diversas categorías vasculares, si bien la introducción de novedades a través del comercio internacional debió ser las más de las veces fruto de la actividad interpretativa de los alfares gadiritas, que introducirían sus propias versiones en territorio indígena. De cualquier forma, es esta una línea de investigación a profundizar en los próximos años, en paralelo al análisis de la difusión de elementos tecnológicos de la producción cerámica (hornos, útiles y procedimientos) en el mundo ibero-turdetano.

El conjunto de formas analizado muestra claramente la pervivencia en evolución de formas tradicionales del repertorio gadirita (caso de los tipos 1.2.0, 2, 3, 4, 7, 8, 9 y 12.3.0) vigentes según el caso en los ss. -V/-IV o aún antes. Sin embargo, no parece tratarse de un grupo fuerte y compacto frente a las injerencias tipológicas foráneas, sino más bien un repertorio en retroceso frente a las cada vez más novedades que llegan de ultramar. Como señalábamos antes, el repertorio que ahora encontramos es en definitiva producto de la evolución de las formas fenicias-occidentales de la etapa arcaica-púnica, de las influencias foráneas coetáneas especialmente, del repertorio consolidado a partir de aquellas y fijado en la segunda mitad del s. -VI (Ruiz Mata 1997). Será en estos momentos, y sobre todo desde el último cuarto de la centuria, cuando encontramos ya una conexión evolutiva lineal con muchas de las formas predominantes en los Ss. -III/-II.

Por otro lado, es necesario señalar el protagonismo de las influencias externas: hay que resaltar que éstas (desde sus inicios) fueron sin duda deudoras de las fluidas relaciones comerciales establecidas por Gadir en diversos momentos ${ }^{14}$ (Sáez, Montero y Díaz 2004). La introducción de profundos cambios tipológicos en el repertorio local y de formas exógenas como los cuencos-mortero del tipo $6 \mathrm{a}$ en el s. -IV podemos entenderlas fácilmente de las fluidas relaciones con el eje comercial

14. Si bien otros autores han resaltado las diferencias con los repertorios comunes manufacturados en Cartago e Ibiza (Niveau 2004: 14, nota 36), no cabe duda de la interacción tipológica de todas estas vajillas, siendo de notable interés resaltar las afinidades productivas durante los ss. -IV a -II en el binomio Gadir-Ibiza. Algunas formas como las 3.2.1, 10.4.0, los ungüentarios y algunas variantes de la 11.1.1 reflejan claramente estas relaciones. 
Ibiza-Ampurias en la primera mitad de la centuria y de la crisis del último tercio del siglo que acercó sin duda a Gadir a la órbita cultural cartaginesa ante la inoperancia político-económica para continuar sus relaciones con el mundo griego. El creciente número de formas relacionable con los repertorios centromediterráneos documentado en el s. -III y especialmente tras la ocupación bárcida (en lo cual Ibiza tuvo un papel principal) representa la culminación de ese proceso iniciado en el -IV, pero con la sustancial diferencia de que probablemente en relación con la I Guerra Púnica Gadir ha remontado el vuelo a nivel comercial y está restableciendo su lazos económicos anteriores al "control" cartaginés.

Otra cuestión de capital importancia que podemos ahora plantear al hilo de esta propuesta tipológica es la supuesta capacidad del repertorio de vajilla barnizado para llegar "incluso a sustituir a sus correspondientes en cerámica común" (Niveau 2001: 122). Esta hipótesis argumentada esencialmente en base al estudio de conjuntos cerámicos de la última fase del CDB y del poblado de Las Cumbres, contrasta desde luego con los datos mostrados por los desechos de la actividad de los alfares gadiritas coetáneos. Para argumentar nuestras discrepancias nos centraremos en el análisis sólo de algunas de las formas incluidas en nuestra tipología, las más significativas al respecto, lo que nos servirá para intentar demostrar que ambas categorías (comunes y barnizadas) se complementaron en la conformación del ajuar doméstico gadirita del momento y se influyeron mutuamente a nivel formal. A nivel general destaca el que buena parte de las formas del repertorio barnizado se manufacturaron (algunas a gran escala) en cerámica común: los cuencos de cuarto de esfera, los saleritos, los cuencos de borde entrante medianos, los vasos, los platos de pescado, etc... El elenco tipológico mostrado en nuestra propuesta incluye todas estas formas, con diversas variantes, y otras no presentes en el repertorio barnizado propias quizá de la presentación de alimentos (cuencos carenados de la forma 2) o del servicio de líquidos (jarras de diversos tamaños del grupo 10). La producción de estos elementos de vajilla de mesa o de uso cotidiano fueron manufacturados en cantidades en algunos caso masivas en los alfares gadiritas, destacando la fabricación de algunas categorías como los vasos del tipo 7.1.0, los cuencos de la forma 2 y las jarras de los tipos 10.2.1, 10.3.1 y 10.4.0. La producción del repertorio barnizado alcanzó elevadas cotas cuantitativas en la segunda mitad del s. -III, si bien nunca llegó a ser superior al de las cerámicas comunes. No cabe duda a tenor de lo expuesto que no se dio una sustitución, sino una estrecha relación funcional y formal de ambas clases cerámicas, que en ocasiones compartieron incluso los mismos motivos estampillados a modo de decoración (véanse las ovas de las cazuelas de la forma 11.1.1). Es decir, ambos repertorios tuvieron formas exclusivas y compartieron otras, si bien todas ellas en la práctica debieron combinarse en las mesas gadiritas del momento. Sí es claro el dominio abrumador de las categorías sin tratamiento en tareas más «industriales» o de almacenaje, siendo abundantísimas formas como los cuencos-mortero de la forma 3.2.0, los lebrillos de la forma 4 y sobre todo las tinajas del tipo 8.1.1.

La tipología mostrada en estas páginas nace con la pretensión de convertirse en una herramienta útil para la identificación de contextos de los ss. -III/-II, como un anticipo de nuevas aportaciones que han de venir en un plazo cercano a través de la sistematización de las categorías vasculares de varias alfarerías gadiritas cuyos estudios se encuentran en curso. Al igual que en otros ámbitos del mundo púnico del Mediterráneo centro-occidental como Ibiza (Rodero 1980; Gómez y Gurrea 1985; Fernández y Costa 1995 y 1998) o Cartago (Lancel 1987), nos parece que el estado de las investigaciones sobre las producciones locales gadiritas se encuentra en un momento de madurez apropiado para comenzar a sistematizar todas sus categorías vasculares y para comenzar un análisis crítico de su origen, su funcionalidad y su evolución formal. El repertorio tipológico deberá ser matizado en los próximos años con nuevos contextos que aporten nuevos indicadores cronológicos y estilísticos sobre las formas incluidas ahora $\mathrm{u}$ otras que, como se ha reseñado, esperan ser incluidas debido a su desconocimiento formal en base a la fragmentación de las piezas. 


\section{REFERENCIAS BIBLIOGRÁFICAS}

ADROHER AUROUX, A. M, (1993): "Céramique commune punique", Lattara, 6: 374-378. Lattes.

ARTEAGA, O.; CASTAÑEDA, V.; HERRERO, N. y PÉREZ, M. (2001): “Los hornos tardopúnicos de Torre Alta (San Fernando, Cádiz). Excavación de urgencia de 1997”, Anuario Arqueológico de Andalucia/1997, vol. III: 128-136. Sevilla.

BELÉN, M.; ESCACENA, J. L.; RODERO, A. y LÓPEZ, C., (2000): "Materiales de época fenicia de las excavaciones de Tarradell conservados en el Museo de Tetuán”, en Aranegui, C., (Ed.) Lixus. Colonia fenicia y ciudad púnico-mauritana. Anotaciones sobre su ocupación medieval., Sagvntvm Extra-4: 83-108. Valencia.

BERNAL, D.; DÍAZ, J. J.; EXPÓSITO, J. A.; SÁEZ, A. M.; LORENZO, L. y SÁEZ, A., (2003): Arqueología y Urbanismo. Avance de los hallazgos de época púnica y romana en las obras de la carretera de Camposoto (San Fernando, Cádiz), Jerez de la Frontera.

BIKAI, P. M., (1978): The pottery of Tyre, Guildford.

BONET, H.; KBIRI, M.; VIVES, J. y HASSINI, H., (2000): “La ocupación púnico-mauritana”, en Aranegui, C., (Ed.) Lixus. Colonia fenicia y ciudad púnico-mauritana. Anotaciones sobre su ocupación medieval., Sagvntvm Extra-4: 51-71. Valencia.

CARRILERO, M. y LÓPEZ, J. L., (1994): “Ciavieja: un asentamiento de época púnica en el poniente almeriense", El Mundo Púnico: Historia, sociedad y cultura (Cartagena, 17-19 de noviembre de 1990), Coloquios de Cartagena I: 252-268. Cartagena.

CASTRO CUREL, Z., (1980): "Fusayolas ibéricas, antecedentes y empleo", Cypsela, III: 127-146. Gerona.

CASTRO CUREL, Z., (1985): "Piezas toroides de arcilla en yacimientos ibéricos", Cypsela, V: 125-142. Gerona.

CURIÁ, E., DELGADO, A., FERNÁNDEZ, A. y PÁRRAGA, M., (1999): "Estudio de los materiales. La cerámica a torno fenicia", en AUBET, M. E. et alii, Cerro del Villar-I. El asentamiento fenicio en la desembocadura del río Guadalhorce y su interacción con el hinterland, Arqueología Monografías: 157-277. Sevilla.

DONATI, A., "Un mare di pesci", en Donati, A., y Pasini, P., (Eds.) Pesca e pescatori nell'antichitá: 7-44. Milán.

FERNÁNDEZ, J. H. y COSTA, B., (1995): "La cerámica común púnico-ebusitana: Las formas principales y su cronología”, Actas del III CIEFP (Túnez, 1991), II: 10-25. Túnez.

FERNÁNDEZ, J. H. y COSTA, B., (1998): "La cerámica común púnico-ebusitana: precisiones tipológicas y cronológicas sobre algunas formas cerradas”, Misceláneas de Arqueología Ebusitana I, TMAI 42: 23-82. Ibiza.

FIERRO, J. A., (1990): “Cerámica turdetana en Cádiz”, Revista de Arqueología, 114, Zugarto Ed.: 34-40. Madrid.

GENER, J. M., (1994): "Seguimiento arqueológico en la obra de alcantarillado en la calle Santa Cruz de Tenerife y Avda. de Andalucía (Cádiz)", Anuario Arqueológico de Andalucía/1994, III: 16-20. Puerto Real.

GÓMEZ, C., y GURREA, R., (1985): “Algunas formas de la cerámica de cocina púnico-ebusitana”, AEspA, 58, CSIC: 139-154. Madrid.

GONZÁLEZ, B.; TORRES, J.; LAGÓSTENA, L. e HIGUERAS, A. (2002): "Los inicios de la producción anfórica en la bahía gaditana en época republicana: la intervención de urgencia en 
Avda. Pery Junquera (San Fernando, Cádiz)", Congreso Internacional Ex Baetica Amphorae, I: 175-186. Sevilla-Écija, 1998.

GORDILLO, A. M., (1987): "Los recipientes de incineración romanos depositados en el Museo de Cádiz", Anuario Arqueológico de Andalucía/1985, II: 465-470. Sevilla.

GUERRERO, V. M., (1995): "La vajilla púnica de usos culinarios", RSF, XXIII, 1: 61-99. Roma.

GUERRERO, V. M., (1999a): "Elementos de la vajilla de mesa púnica en Baleares", XXIV CNA (Cartagena, 1997), III: 177-190. Murcia.

GUERRERO, V. M., (1999b): La cerámica protohistórica a torno de Mallorca (s. VI-I a.C.), BAR International Series 770, Oxford.

GUTIÉRREZ, J. M., (1999): “Tartésicos y turdetanos en el interior de Cádiz. Torrevieja (Villamartín), un yacimiento en la cuenca media del Guadalete", Revista de Arqueología, 217: 26-35. Zugarto Ed., Madrid.

GUTIÉRREZ, J. M., (2000): “Aportaciones a la producción de salazones de Gadir: la factoría púnico-gaditana Puerto 19", Revista de Historia de El Puerto, 24: 11-46. El Puerto de Santa María.

LANCEL, S., (1982): “L’ilot E”, Byrsa II. Misión archéologique francaise a Carthage, Colección de la Escuela Francesa de Roma, 41: 106-141. Roma.

LANCEL, S., (1987): “La ceramique punique d'epoque hellénistique”, Cerámiques Hellénistiques et Romaines II, Annales Littéraries de l'Université de Besancon 331: 99-137. París.

LANCEL, S., y THUILLIER, J. P., (1979): "Rapport préliminaire sur la campagne de 1976 (Niveaux puniques)", Byrsa I. Misión archéologique francaise a Carthage, Colección de la Escuela Francesa de Roma, 41: 187-270. Roma.

LÓPEZ DE LA ORDEN, M. D., (2003): "Urnas cinerarias de la necrópolis romana de Cádiz", Anuario Arqueológico de Andalucía/2000, II: 111-116. Sevilla.

LUZÓN NOGUÉ, J. M. (1973): "Excavaciones en Itálica. Estratigrafía en el Pajar de Artillo", Excavaciones Arqueológicas en España, 78, Madrid.

MARTÍN CAMINO, M., (1998) "Un contexto cerámico de finales del siglo III a. C.: el vertedero púnico de la Plaza de San Ginés (Cartagena)", Arqueomediterránia, 4: 9-28. Barcelona.

MARTÍN RUIZ, J. A., (1995): Catálogo documental de los fenicios en Andalucía, Junta de Andalucía, Sevilla.

MARTÍNEZ, A. y CASTELLANO, J. J., (1995): “Conjunto de fusayolas ibéricas de dos cuevas santuario de la comarca de Requena-Utiel”, XXIII Congreso Nacional de Arqueología, I: 525536. Elche.

MONTERO, A. I., MONTERO, R., SÁEZ, A. y DÍAZ, J. J. (2004): “Innovaciones, transformaciones y pervivencias. Evolución de la alfarería gadirita durante los ss. III-II a.n.e.", Actas del Congreso Internacional Figlinae Baeticae. Talleres Alfareros y producciones cerámicas en la Bética romana (ss. II a.C. - VII d.C.), BAR International Series 1266, II: 413-426. Oxford.

MUÑOZ VICENTE, A., (1982): "Una lucerna de dos picos en la necrópolis gaditana", Bol. Museo Cádiz, III: 43-46. Cádiz.

MUÑOZ VICENTE, A., (1985): "Las ánforas prerromanas de Cádiz (Informe Preliminar)", AnArqAnd/85: 472-478. Sevilla.

MUÑOZ VICENTE, A., (1987a): Las cerámicas fenicio-púnicas de Cádiz. Memoria de Licenciatura Inédita. Universidad de Sevilla.

MUÑOZ VICENTE, A., (1987b): "Avance sobre el estudio de los ungüentarios helenísticos de Cádiz. 1986”, Anuario Arqueológico de Andalucía/1986, II: 520-525. Sevilla. 
MUÑOZ VICENTE, A., (1993a): "Las cerámicas fenicio-púnicas de origen submarino del área de la Caleta (Cádiz)", Cuadernos de Prehistoria y Arqueología Castellonenses, ${ }^{\circ}{ }^{\circ}$ 15, Castellón.

MUÑOZ VICENTE, A., (1993b): "En tomo a seis askoi zoomorfos de la necrópolis púnica de Cádiz”, Bol. Museo Cádiz, V, 1992: 7-15. Cádiz.

MUÑOZ VICENTE, A., (1997): “Secuencia histórica del asentamiento fenicio-púnico de Cádiz: un análisis crono-espacial tras quince años de investigación arqueológica", Boletín del Museo de Cádiz, VII, (1995-1996): 77-105. Cádiz.

MUÑOZ VICENTE, A., (e.p.): "Las ánforas fenicio-púnicas de la Bahía de Cádiz”, Boletín del Museo de Cádiz, VIII, Cádiz 1998.

NIEMEYER, H. G., et alii, (2002): "Excavación bajo el decumanus maximus de Cartago durante los años 1986-1995: informe preliminar", Cartago Fenicio-Púnica. Las excavaciones alemanas en Cartago 1975-1997, Cuadernos de Arqueología Mediterránea, 4: 47-109. Barcelona.

NIVEAU, A. M., (1999): “Ánforas turdetanas, mediterráneas y púnicas del s. III del Castillo de Doña Blanca (El Puerto de Santa María, Cádiz)", XXIV Congreso Nacional de Arqueología, vol. 3: 133-140. Cartagena 1997.

NIVEAU, A. M., (2000a): "La producción de cerámicas rojas de tradición griega en la zona de Cádiz. Las cerámicas de tipo 'Kuass': una nueva perspectiva”, MM, 41: 178-196. Mainz.

NIVEAU, A. M., (2000b): "La cerámica 'tipo Kuass'. Avance a la sistematización del taller gaditano", Spal, 8: 115-134. Sevilla 1999. http://dx.doi.org/10.12795/spal.1999.i8.07

NIVEAU, A. M., (2001): "Pozos púnicos en la necrópolis de Cádiz: evidencias de prácticas rituales funerarias", Rivista de Studi Fenici, XXIX, 2, CNR: 183-230. Roma.

NIVEAU, A. M., (2002): Las cerámicas gaditanas barnizadas de "tipo Kuass”. Tipología, producción y distribución., Tesis Doctoral inédita, Universidad de Cádiz.

NIVEAU, A. M., (2003): Cerámicas gaditanas “tipo Kuass”, Bibliotheca Archaeologica Hispana, 21, Madrid.

NIVEAU, A. M., (2004a): "El uso ritual de la vajilla cerámica en la necrópolis púnica de Cádiz", AEspA, 76, CSIC: 3-30. Madrid.

NIVEAU, A. M., (2004b): "La producción de cerámicas barnizadas «tipo Kuass» en la Bahía de Cádiz", Actas de los XVI Encuentros de Historia y Arqueología de San Fernando. Las industrias alfareras y conserveras fenicio-púnicas de la Bahía de Cádiz (noviembre de 2000): 171-200. San Fernando.

PERDIGONES, L., MUÑOZ, A. y MARCOS, A., (1987): "Excavaciones de urgencia en un solar de la Avda. Andalucía esquina Plaza de Asdrúbal (Cádiz)", Anuario Arqueológico de Andalucía/1986, III, Sevilla.

PÉREZ HORMAECHE, E., (1990): “Arqueología gaditana 1: Quemaperfumes púnicos”, Gades, 9: 9-23. Cádiz.

PÉREZ HORMAECHE, E., (1993): “Arqueología gaditana 2: ungüentarios púnicos”, Gades, 11: 261-268. Cádiz.

PONSICH, M., (1968): “Alfarerías de época fenicia y púnico-mauritana en Kuass (Arcila, Marruecos)", Papeles del Laboratorio de Arqueología de Valencia, 4, Valencia.

PRITCHARD, J. B., (1978): Recovering Sarepta, a phoenician city, Princeton University Press, New Jersey.

RAMÓN, J., (1995): Las ánforas fenicio-púnicas del Mediterráneo Central y Occidental, Universitat de Barcelona, Colección Instrumenta, 2, Barcelona. 
RAMÓN, J., (1997): FE-13. Un taller de alfarero de época púnica en Ses Figueretes (Eivissa), TMAI, 39, Ibiza.

RAMÓN, J., (1998a): "Barrio industrial de la ciudad púnica de Eivissa: el taller AE-20", Misceláneas de Arqueología Ebusitana, I, TMAI, 42: 167-215. Ibiza.

RAMÓN, J., (1998b): "Un depósito de cerámicas del siglo V a.C. en Es Palmer (Eivissa)", Misceláneas de Arqueología Ebusitana, I, TMAI, 42: 131-143. Ibiza.

RAMÓN, J., (2004): "La producción anfórica gaditana en época fenicio-púnica", Actas de los XVI Encuentros de Historia y Arqueología de San Fernando. Las industrias alfareras y conserveras fenicio-púnicas de la Bahía de Cádiz (noviembre de 2000): 63-100. Fundación Municipal de Cultura, San Fernando.

RAMÓN, J.; SÁEZ, A.; SÁEZ, A. M. y MUÑOZ, A., (2004): El taller alfarero tardoarcaico de Camposoto, Monografías de Arqueología, Junta de Andalucía, en prensa.

RODERO, A., (1980): Colección de cerámica púnica de Ibiza, MAN, Madrid.

RUIZ MATA, D., (1986): "Las cerámicas fenicias del Castillo de Doña Blanca (Puerto de Santa María, Cádiz)", Aula Orientalis, II, 1-2: 241-264. Sabadell (Barcelona).

RUIZ MATA, D., (1997): "Fenicios, tartesios y turdetanos", Huelva Arqueológica, XIV, Actas del Congreso "La Andalucía Ibero-turdetana" (Palos de la Frontera, 16-18 de marzo de 1994): 325366. Dip. de Huelva, Huelva.

RUIZ MATA, D., (1998): "Turdetanos: origen, territorio y delimitación del tiempo histórico", Revista de Estudios Ibéricos, 3, UAM, Madrid.

RUIZ MATA, D., (1999): "La fundación de Gadir y el Castillo de Doña Blanca: contrastación textual y arqueológica", Complutum, 10: 279-317. Universidad Complutense de Madrid.

RUIZ, D. y PÉREZ, C., (1995): El poblado fenicio del Castillo de Doña Blanca (El Puerto de Santa María, Cádiz), Colección de Temas Portuenses, 5, El Puerto de Santa María.

RUIZ, D. y NIVEAU, A. M., (1999): "La zona industrial de las Cumbres y la cerámica del s. III a.n.e. (Castillo de Doña Blanca-El Puerto de Santa María, Cádiz)”, XXIV CNA, vol. 3: 125-131. Cartagena 1997.

SÁEZ ROMERO, A. M., (2004): "El alfar tardopúnico de Torre Alta. Resultados de las excavaciones de 2002-2003", Actas del Congreso Internacional Figlinae Baeticae (Cádiz, noviembre 2003), BAR International Series 1266, II: 699-712. Oxford.

SÁEZ ROMERO, A. M., (2005): "Algunas consideraciones acerca de las ánforas gadiritas Mañá-Pascual A4 evolucionadas", XXVII Congreso Nacional de Arqueología (Huesca, mayo 2003), Bolskan, 19 (2002), IEA: 261-275. Huesca.

SÁEZ, A.; DÍAZ, J. J. y MONTERO, R., (2004): “Acerca de un tipo de ánfora salazonera púnico-gadirita", Habis, 35: 109-133. Sevilla.

SÁEZ, A. M., MONTERO, A. I. y DÍAZ, J. J., (2005): "La producción alfarera de época púnica en Gadir (ss. VI-IV a.n.e.)", en A. Blanco, C. Cancelo y A. Esparza (Eds.) Bronce Final y Edad de Hierro en la Península Ibérica. Encuentro de Jóvenes Investigadores (Universidad de Salamanca, octubre de 2003), Colección Aquilafuente, 86: 479-501. Fundación Duques de Soria, USal, Salamanca.

SÁEZ, A. M.; MONTERO, R.; MONTERO, A. I. y DÍAZ, J. J., (e.p.): "Novedades acerca de los talleres cerámicos de Gadir", Byrsa. Rivista di arte, cultura e archeologia del Mediterráneo punico, 2, Agora Edizioni. 
THUILLIER, J. P., (1982): "Le secteur nord-est de L'ilot C et les niveaux de la Rue IV”, Byrsa II. Misión archéologique francaise a Carthage, Colección de la Escuela Francesa de Roma, 41: 61-84. Roma.

VEGAS, M., (2000): "La cerámica fenicia del siglo VIII en Cartago", Actas del IV CIEFP (Cádiz, 1995), vol. IV: 1237-1246. Cádiz.

VEGAS, M., (2002): “Alfares arcaicos en Cartago", Cartago Fenicio-Púnica. Las excavaciones alemanas en Cartago 1975-1997, Cuadernos de Arqueología Mediterránea, 4: 147-164. Barcelona. 

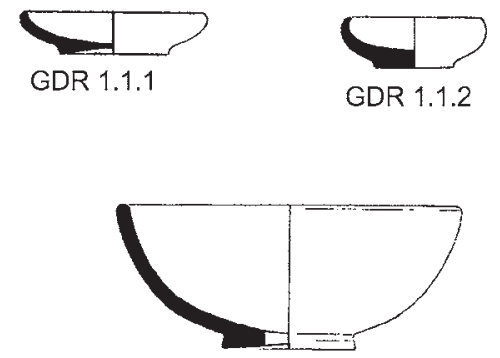

GDR 1.3.1

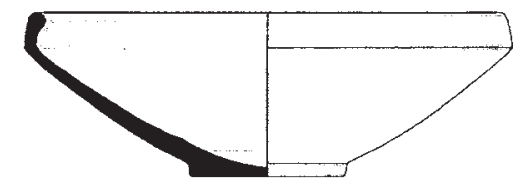

GDR 2.1.1

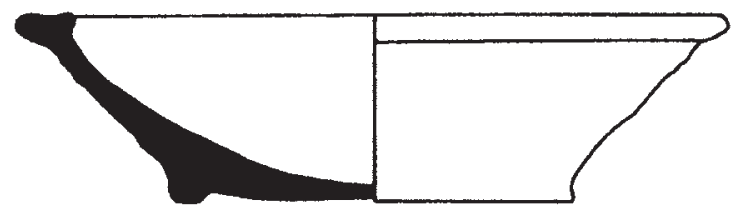

GDR 3.1.1

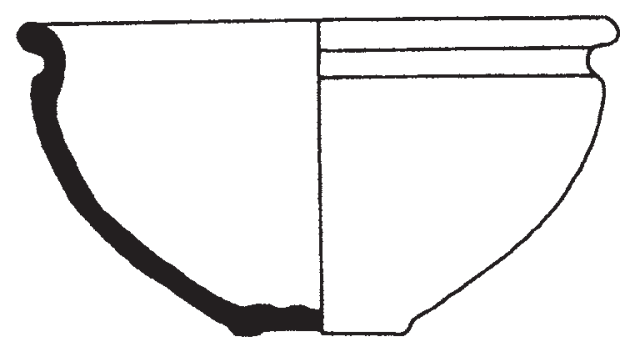

GDR 4.1.1

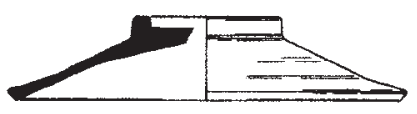

GDR 6.1.1

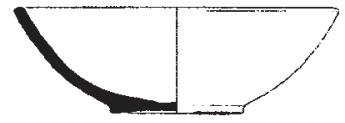

GDR 1.2.1

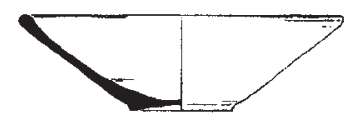

GDR 1.2 .3
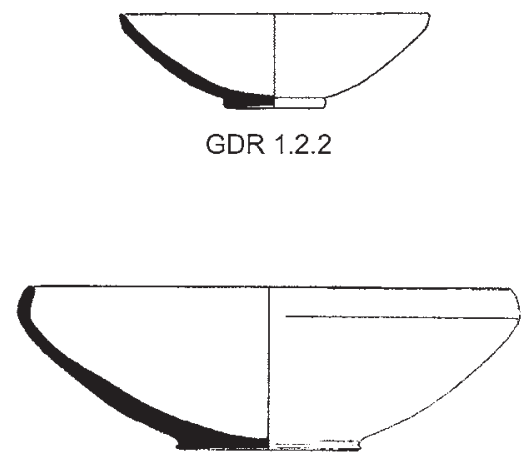

GDR 2.1.2

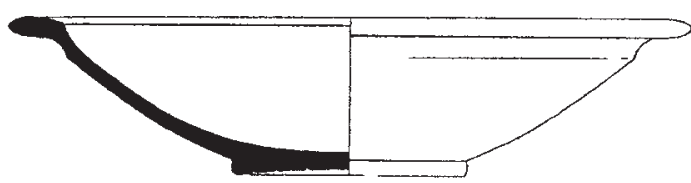

GDR 3.2.1
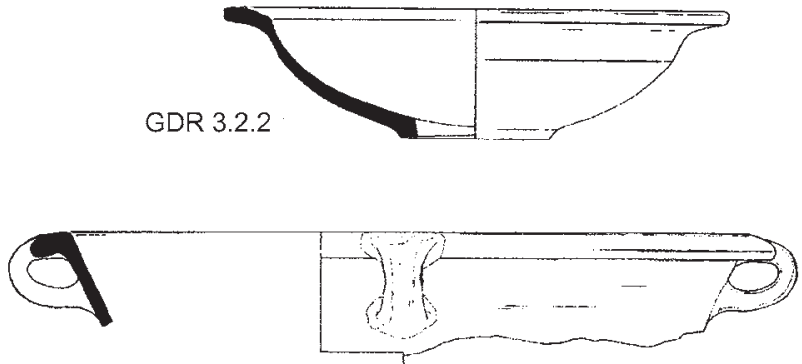

GDR 4.1.2
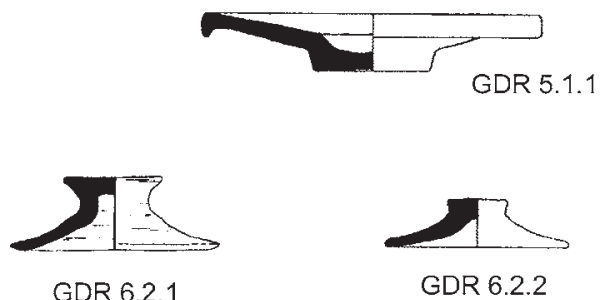

GDR 6.2 .1

Figura 1.- Tipología de las formas comunes gadiritas: cuencos, páteras, morteros, platos y tapaderas. 


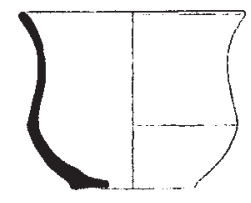

GDR 7.1.

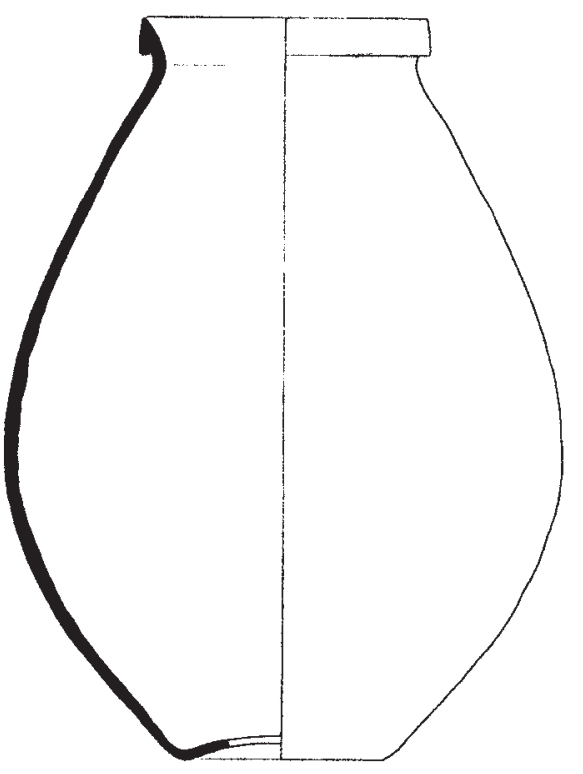

GDR 8.1.1
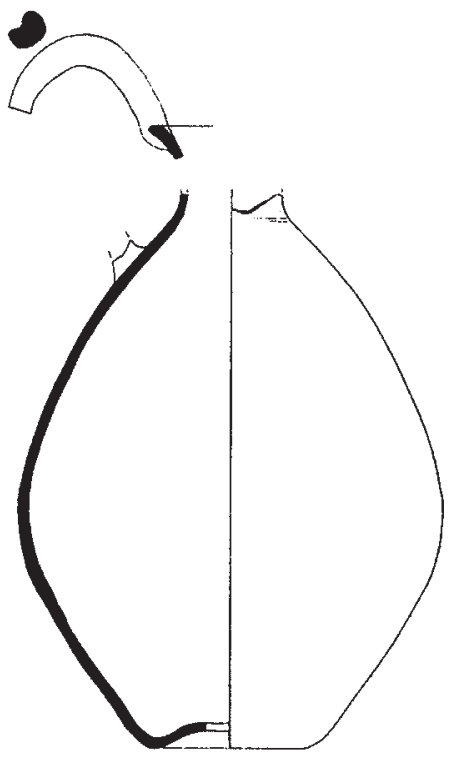

GDR 10.1.1

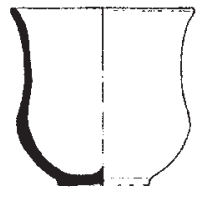

GDR 7.1.2

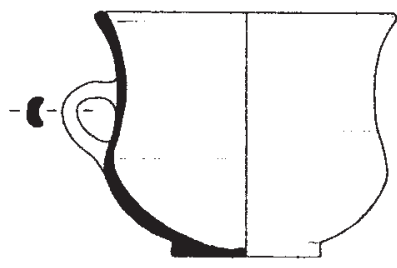

GDR 7.2.1

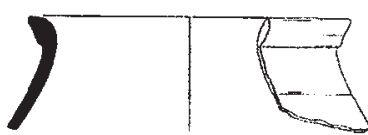

GDR 8.1.2

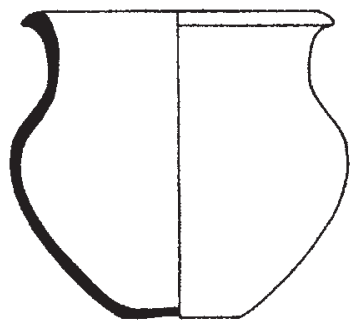

GDR 9.1.1
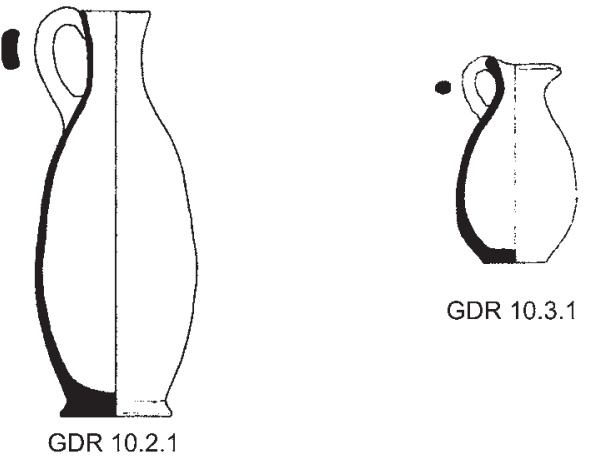

GDR 10.3.1

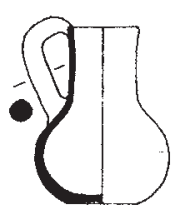

GDR 10.4.1

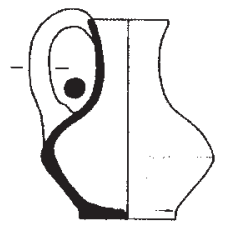

GDR 10.4.2

Figura 2.- Tipología de las formas comunes gadiritas: vasos, tinajas y jarras. 


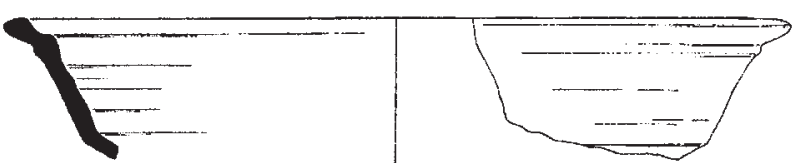

GDR 11.1.1

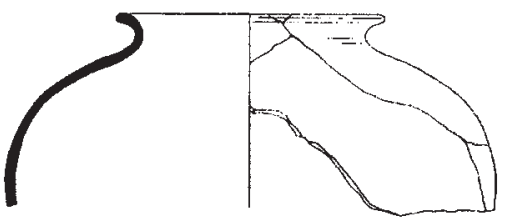

GDR 12.1.1

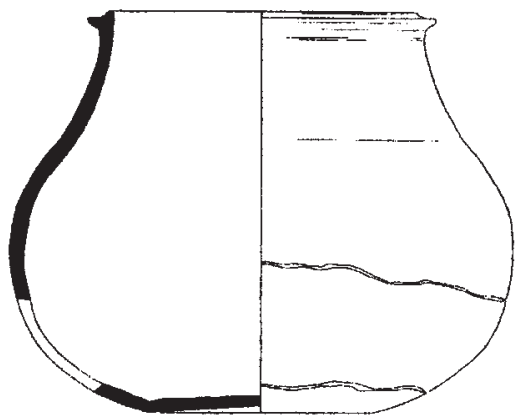

GDR 12.3.1

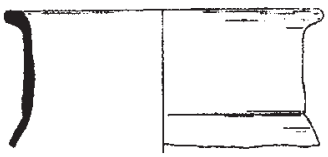

GDR 12.3.2

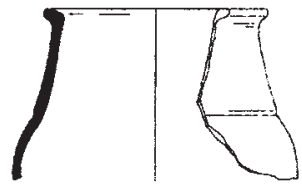

GDR 12.4.1

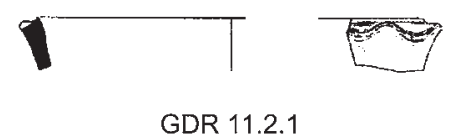

GDR 11.2.1

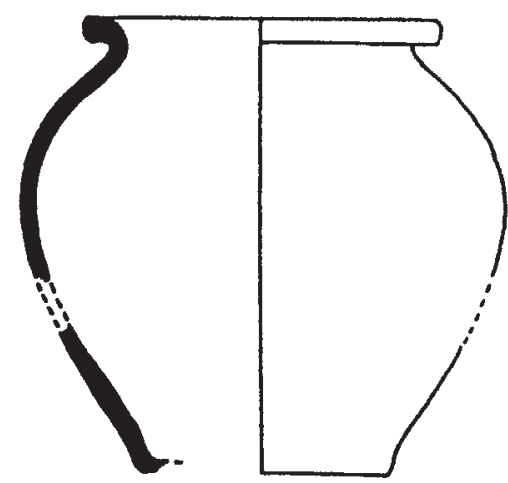

GDR 12.2.1
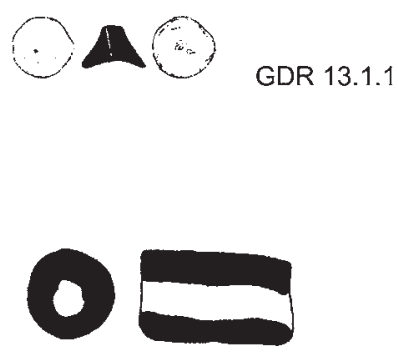

GDR 14.1.1

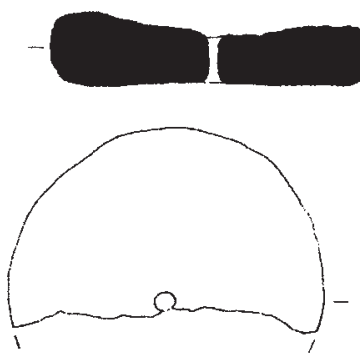

GDR 14.2.1

Figura 3.- Tipología de las formas comunes gadiritas: cazuelas, ollas, fusayolas y pesas. 